\title{
Estrutura de um trecho de floresta Amazônica na bacia do alto rio Xingu.
}

\author{
Natália Macedo IVANAUSKAS ${ }^{1}$, Reinaldo MONTEIRO², Ricardo Ribeiro RODRIGUES ${ }^{3}$
}

\begin{abstract}
RESUMO
Este estudo apresenta a estrutura de florestas em Gaúcha do Norte-MT $\left(13^{\circ} 10^{\prime} \mathrm{S}\right.$ e $\left.53^{\circ} 15^{\prime} \mathrm{O}\right)$, na borda sul-amazônica. Para o levantamento fitossociológico, três áreas amostrais de 1 ha foram subdivididas em 50 parcelas de 10x20m, nas quais foram amostrados todos os indivíduos com perímetro à altura do peito (PAP) $\geqslant 15 \mathrm{~cm}$. Para verificar a similaridade estrutural entre as áreas utilizou-se a Análise de Correspondência. As espécies indicadoras dos ambientes de interflúvio e das áreas sujeitas à inundação foram obtidas através do TWINSPAN e de um sistema de pesos. Concluiu-se que as florestas presentes na bacia do rio Pacuneiro pertencem à mesma unidade fitogeográfica, mas com subtipos florísticos e estruturais de acordo com a posição no relevo, a proximidade dos cursos d'água e o estrato analisado, apresentando predominância de algumas espécies, ou até mesmo possíveis endemismos, em determinados trechos ou estratos. A formação apresentou baixa diversidade alfa $(2,91$ a 3,50) e beta $(3,62$ a 3,86), o que não é comum em florestas amazônicas. Várias hipóteses podem explicar essa baixa diversidade, entre elas a baixa precipitação e a alta sazonalidade, o ambiente físico regional aparentemente homogêneo e favorável às espécies competidoras, ou os eventos históricos, relacionados à possível exploração por tribos indígenas ou à recente expansão dessas florestas sobre as áreas savânicas.
\end{abstract}

PALAVRAS-CHAVE

Amazônia, Xingu, floresta Amazônica, estrutura florestal.

\section{Structure of patch of Amazonian forest in the alto rio Xingu basin.}

\begin{abstract}
This paper shows the structure of patch of forest at Gaúch a do Norte-MT (13 $13^{\circ} 10^{\prime} \mathrm{S}$ e $\left.53^{\circ} 15^{\prime} \mathrm{O}\right)$ in southern Amazonia. For the phytosociological survey, the 3 sample areas of 1 ha were subdivided into 50 sections of $10 \times 20 \mathrm{~m}$. All the individuals with circumference at breast height $(\mathrm{CBH}) \geqslant 15 \mathrm{~cm}$ were sampled. To characterise the structural similarity between the areas, correspondence analysis (CA) was used. The indicator species of the interfluvial environments and of the areas subject to flooding were obtained using TWINSPAN (Two way indicator species analysis) and a system of weights. It was observed that the forests present in the Pacuneiro river basin belong to the same phytogeographical unit, but may present floristic and structural subtypes according to the relief position, the proximity to rivers and streams and the stratum analysed, demonstrating the predominance of some species, or even possible endemic species, in certain areas or stratums. The formation demonstrated a comparatively low alpha (2.91 - 3.50) and beta beta diversity (3.62 a 3.86) which is not common in Amazonian forests. Various hypothesis may explain this diversity, such as the low rainfall and high seasonallity, the apparently bomogenous regional physical environment favourable to competing species, or historic events such as possible exploration by indigenous tribes or the recent expansion of these forests over savannic areas.
\end{abstract}

\section{KEY WORDS}

Amazonia, Xingu, tropical rain forest, tropical evergreen forest, forest structure

\footnotetext{
${ }^{1}$ Departamento de Biologia, Instituto de Ciências Naturais e Tecnológicas, Universidade do Estado de Mato Grosso, Caixa Postal 08, 78690-000 - Nova Xavantina-MT.nivanaus@yahoo.com.br

${ }^{2}$ Departamento de Botânica, Instituto de Biociências, Universidade Estadual Paulista, 13.506-900, Rio Claro-SP. reimonte@rc.unesp.br

${ }^{3}$ Departamento de Ciências Biológicas, Escola Superior de Agricultura "Luiz de Queiroz",Universidade de São Paulo, Caixa Postal 09, 13418-900 Piracicaba - SP. rrr@esalq.usp.br. Autor para correspondência.
} 


\section{ACTA AMAZONICA}

ESTRUTURA DE UM TRECHO DE FLORESTA

AMAZÔNICA NA BACIA DO ALTO RIO XINGU

\section{INTRODUÇÃO}

A expansão da fronteira agrícola vem exercendo grande pressão de desmatamento sobre extensas áreas de Cerrado e, nas últimas décadas, também sobre a Floresta Ombrófila. A indústria madeireira, migrante da região sul do país, está se expandindo e explorando o potencial das florestas presentes na região norte do Mato Grosso (Ackerly et al, 1989; Martini et al, 1998; SEPLAN/MT, 1999). Já as queimadas vêm se tornando cada vez mais freqüentes, tanto nas áreas savânicas quanto nas áreas florestais (Fearnside, 1990). A ampliação da malha viária e a possível expansão das hidrovias contribuem para acelerar os processos de degradação sobre esses ecossistemas (Salomão \& Lisboa, 1988).

A caracterização fitossociológica de formações naturais é uma linha de pesquisa recente no Estado de Mato Grosso, sendo poucos os trabalhos publicados até o momento (Salis et al., 1999), apesar da grande variedade de formações vegetais presentes no Estado (SEPLAN/MT, 1999).

O mapeamento, o levantamento florístico e a descrição da estrutura de vários remanescentes destas formações, foram alguns dos objetivos a serem alcançados por dois grandes projetos: o Plano de Conservação da Bacia do Alto Paraguai (PCBAP) e o PRODEAGRO. Apesar da importância dos resultados apresentados, estes projetos se fundamentaram em levantamentos fitossociológicos realizados num único período e com pequenas áreas amostrais, o que dificultou as coletas de material reprodutivo, resultando em problemas de amostragem e em listagens com elevado número de espécies indeterminadas.

Levantamentos fitossociológicos mais acurados foram realizados principalmente no centro-sul do Estado, nas formações florestais e savânicas presentes em áreas com grande potencial turístico, como a região do pantanal matogrossense (Prance \& Schaller, 1982; Nascimento \& Cunha, 1989; Dubs, 1992; Haase, 1999) ou em Chapada dos Guimarães (Oliveira-Filho \& Martins, 1986; Nascimento \& Saddi, 1992; Oliveira-Filho, 1992). Além destes, trabalhos pontuais foram realizados no cerrado próximo à Cuiabá (Guarim-Neto et al., 1994) ou em Nova Xavantina (Marimon et al., 1998).

A estrutura de florestas de galeria presentes no centrosul de Mato Grosso foi apresentada por Oliveira-Filho (1989) e Pinto \& Oliveira-Filho (1999). Trabalhos sobre a Floresta Estacional do leste do Estado foram publicados por Marimon \& Felfilli (1997, 2000) e Felfilli et al. (1998), e não existem levantamentos fitossociológicos detalhados sobre as Florestas Ombrófilas matogrossenses.

Deste modo, foram poucos os inventários realizados no Mato Grosso até o momento, o que impede a adequada caracterização da flora e dos fatores condicionantes das diversas formações vegetais presentes no Estado (Maciel \& Lisboa, 1989). Menos se sabe ainda sobre as relações florísticas entre cada fitofisionomia.
Neste panorama, a bacia do Rio Xingu encontra-se em condições privilegiadas, pois grande parte da área encontrase no interior do Parque Indígena do Xingu, reduzindo a probabilidade de exploração madeireira ou o corte raso a curto prazo. No entanto, todas as nascentes dos rios que formam o Xingu encontram-se fora do Parque, e portanto estão sujeitas ao impacto da ação antrópica, podendo atingir as comunidades silvícolas que habitam o interior desta reserva indígena e as do entorno (Figura 1).

Especificamente na bacia do Rio Xingu, o único trabalho fitossociológico publicado não foi realizado no Mato Grosso, Estado que abriga grande parte da bacia, e sim no Pará, na região do baixo Xingu (Campbell et al., 1986).

Deste modo, o conhecimento da estrutura e da composição florística das formações vegetais presentes nas cabeceiras dos formadores do Rio Xingu, tornam-se vitais para o planejamento do uso desta bacia, objetivando a conservação da biota presente em seu interior, assim como para fornecer subsídios para a revegetação das áreas já degradadas (Rodrigues \& Leitão Filho, 2000). Além do mais, embora levantamentos estritamente florísticos permitam comparações relativamente simples e eficientes entre um grande número de áreas, diferenças e semelhanças entre áreas geograficamente próximas e/ou

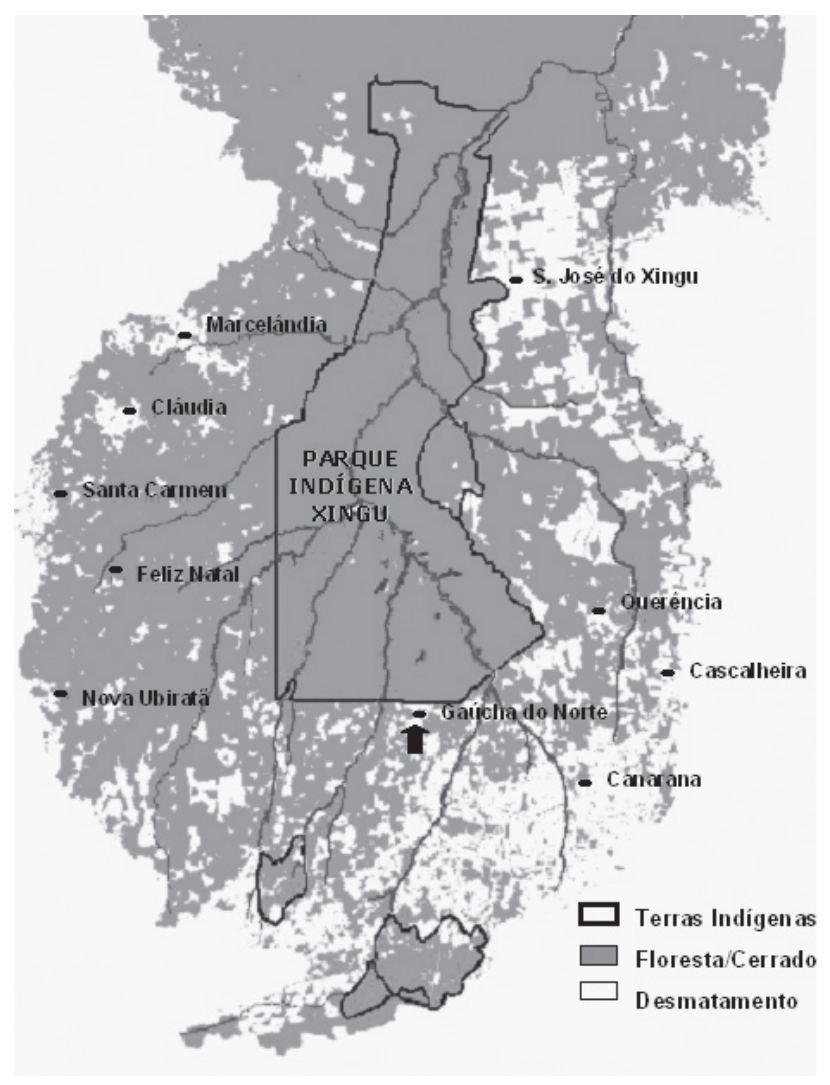

Figura 1 - Cobertura vegetal da Bacia do Rio Xingu, incluindo as sedes municipais e as reservas indígenas. Destaque para o município de Gaúcha do Norte, indicado pela seta. Disponível na Internet via WWW. URL: http://www.isa.org.br. 


\section{ACTA AMAZONICA}

floristicamente parecidas podem ser melhor acessadas através de dados quantitativos fornecidos por levantamentos fitossociológicos (van den Berg, 1995).

Neste contexto, este trabalho pretende colaborar para o conhecimento das formações vegetais presentes ao redor do Parque Indígena, apresentando a estrutura fitossociológica da floresta presente na microbacia do Rio Pacuneiro, pertencente à bacia do Alto Xingu, no Estado de Mato Grosso. O objetivo é verificar se existem diferenças estruturais na comunidade florestal entre as áreas de interflúvio e as áreas ribeirinhas e as possíveis espécies indicadoras de cada situação, a fim de subsidiar planos de conservação e recomposição florestal da Bacia do Rio Xingu.

\section{MATERIAL E MÉTODOS}

Aárea de estudo localiza-se no município de Gaúcha do Norte-MT ( $13^{\circ} 10^{\prime}$ S e $53^{\circ} 15^{\prime} \mathrm{O}, 390 \mathrm{~m}$ de altitude, Figura 1), sob clima Tropical de Savana (Aw) segundo Köppen (1948).

A identificação das diferentes fitofisionomias presentes no município foi realizada após a análise de fotocópia de imagem LANDSAT 5 - TM, escala 1:250.000, datada de 12/07/1994 e contendo uma composição colorida em falsa cor das bandas espectrais TM3, TM4 e TM5. Esta imagem foi correlacionada com o mapa de solos da região (Jacomine et al., 1995).

As visitas ao local permitiram verificar alterações no relevo e na fisionomia da vegetação. Através de um levantamento expedito, que levou em consideração a fisionomia da vegetação e as espécies de maior ocorrência, foram caracterizadas e locadas na imagem os tipos de vegetação existentes no local (CNEC, 1997). Finalmente, para a escolha dos trechos de floresta onde foram realizados os levantamentos fitossociológicos, levou-se em consideração a posição no relevo, o tipo de solo, o grau de preservação da área e a facilidade de acesso. Foram definidas três áreas de estudo:

Área 1 - propriedade do Sr. Lauri Stoffel $\left(13^{\circ} 12^{\prime} \mathrm{S}\right.$ e $53^{\circ} 20^{\prime} \mathrm{O}, 337 \mathrm{~m}$ de altitude). Floresta sobre Latossolo Vermelho-Amarelo, localizada no interflúvio da margem direita do Rio Pacuneiro.

Área 2 - Fazenda Boa Esperança, propriedade do Sr. Alfredo Zingler ( $13^{\circ} 10^{\prime} \mathrm{S}$ e $53^{\circ} 27^{\prime} \mathrm{O}, 357 \mathrm{~m}$ de altitude). Floresta sobre Latossolo Vermelho-Amarelo, localizada no interflúvio da margem esquerda do Rio Pacuneiro.

Área 3 - Fazenda Pontal, propriedade do Sr. Silvino Perotto $\left(13^{\circ} 06^{\prime} \mathrm{S}\right.$ e $53^{\circ} 23^{\prime} \mathrm{O}, 314 \mathrm{~m}$ de altitude). Floresta com influência fluvial sazonal (ribeirinha) sobre Neossolo, localizada na margem esquerda do Rio Pacuneiro, a cerca de $50 \mathrm{~m}$ do curso d'água principal.

Para a análise do estrato arbustivo-arbóreo das florestas de interflúvio (áreas 1 e 2), foi instalada em cada local uma parcela quadrada de $100 \times 100 \mathrm{~m}$, subdividida em 50 subparcelas de $10 \times 20 \mathrm{~m}$, que é o desenho recomendado por Ferreira \& Prance (1998) para estudar padrões de abundância de famílias ou de espécies.
Apenas na floresta ribeirinha (área 3) o formato quadrado de 100x100m não pode ser mantido, devido à presença de muitos lagos nessa faixa aluvial, mesmo no período seco, resultantes do afloramento do lençol freático em depressões do terreno. Optou-se então por uma parcela retangular de 50x200m, locada entre dois lagos, também subdividida em subparcelas de $10 \times 20 \mathrm{~m}$, sendo a lateral de maior extensão $(200 \mathrm{~m})$ paralela à margem do rio e distanciada deste cerca de $50 \mathrm{~m}$.

Nestas parcelas foram amostrados todos os indivíduos com perímetro à altura do peito $(\mathrm{PAP}) \geqslant 15 \mathrm{~cm}$, exceto para os indivíduos que perfilharam acima do solo e abaixo da altura do peito $(1,30 \mathrm{~m})$. Para estes, foi adotado o seguinte critério: o indivíduo foi incluído quando pelo menos uma das ramificações obedecia ao critério de inclusão (PAP $\geqslant$ $15 \mathrm{~cm}$ ), sendo então anotado o PAP de todas as ramificações para o cálculo da área basal. Para cada indivíduo amostrado foram anotados valores de PAP, a altura (distância do ápice da copa ao solo, numa linha perpendicular a este), a espécie e observações de campo.

Coletou-se material botânico de cada espécie para identificação, realizada por meio de bibliografia adequada e comparação com exsicatas existentes em herbários (ESA, UEC, IAC, SP, SPSF). Espécimes pertencentes a famílias de taxonomia complexa e as indeterminadas foram enviadas para confirmação e/ou identificação por especialistas. Os espécimes foram agrupados em famílias de acordo com o sistema de Cronquist (1988). Após a identificação, o material foi incorporado ao herbário da Escola Superior de Agricultura "Luiz de Queiroz"/USP (ESA), com duplicatas nos herbários da Universidade Estadual de Campinas (UEC), Universidade do Estado de Mato Grosso - campus de Nova Xavantina (NX) e Universidade Estadual Paulista - campus de Rio Claro (HRCB).

Os parâmetros fitossociológicos para as famílias e espécies foram obtidos utilizando-se os programas PREPARE e PARAMS do pacote FITOPAC (Shepherd, 1994), sendo realizadas análises separadas para os indivíduos com perímetro mínimo de $30 \mathrm{~cm}$, o qual é usado em muitos inventários quantitativos da região amazônica para a amostragem dos indivíduos pertencentes ao dossel e emergentes (neste estudo denominado estrato superior), e para os indivíduos entre 15 e $29,9 \mathrm{~cm}$, conforme recomendado por Campbell (1989), visando a amostragem dos demais estratos arbóreos da comunidade localizados sob o dossel (neste estudo denominado estrato inferior).

O índice de valor de importância ecológica de família (IVF) foi calculado pela somatória da diversidade, densidade e dominância relativas, segundo a fórmula proposta por Mori et al. (1983). A diversidade relativa é a razão entre o número de espécies da família pelo número total de espécies. A densidade relativa é o número de indivíduos da família dividido pelo número total de indivíduos e a dominância relativa é a razão entre a área basal da família pela área basal total. 


\section{ACTA AMAZONICA}

ESTRUTURA DE UM TRECHO DE FLORESTA

AMAZÔNICA NA BACIA DO ALTO RIO XINGU
O índice de valor de importância ecológica de espécie (IVI) foi calculado pela somatória da freqüência, densidade e dominância relativas, descritos por Whittaker (1972) e Mueller-Dombois \& Ellemberg (1974).

As espécies foram classificadas em três categorias de densidade, definidas por Almeida et al. (1993): espécies de baixa densidade ( $1 \mathrm{ind} / \mathrm{ha})$, espécies de densidade intermediária ( 2 a $10 \mathrm{ind} / \mathrm{ha}$ ) e de alta densidade (11 ou mais ind/ha).

Para medir o grau de desigualdade da distribuição de indivíduos em determinadas espécies utilizou-se uma adaptação da "curva de Lorenz" (Pinho \& Vasconcelos, 1997), que pode ser derivada a partir do referencial de eixos cartesianos da seguinte maneira: a) classifica-se, num dos eixos, a porcentagem acumulada do número de espécies que possuem um determinado número de indivíduos, b) no outro eixo, classifica-se a porcentagem acumulada de indivíduos calculada para cada porcentagem de espécies obtida no item anterior, c) com estes dados, traça-se a curva correspondente. Neste caso, com a construção desta curva pretende-se responder à seguinte questão: numa determinada floresta, num determinado tempo, em quanto a distribuição de indivíduos entre as espécies é igual; ou, de forma complementar, em quanto diferem.

A similaridade florística entre as áreas foi verificada através dos índices qualitativos de Jaccard (1912) e Sørensen (1948), descritos em van Tongeren (1995). Como medidas de diversidade, utilizou-se o índice de Shannon e o quociente de mistura de Jentsch (Lamprecht, 1962).

Para verificar a similaridade estrutural entre as áreas utilizouse a Análise de Correspondência (CA), que realiza a ordenação das espécies e das áreas de amostragem simultaneamente, permitindo o exame das relações entre ambas numa única análise. A matriz inicial foi elaborada utilizando-se os valores de densidade de todas as espécies presentes em cada área de amostragem e, posteriormente, com a exclusão de espécies de baixa densidade (Pielou, 1984; Causton, 1988; Valentin, 2000). A análise das duas matrizes foi realizada com o auxílio dos programas MATRIZ e ORD, presentes no pacote FITOPAC (Shepherd, 1994), e os resultados obtidos foram os mesmos.

Como problemas de efeito de arco ou a formação de uma curva involuta pela compressão dos extremos do gradiente são comuns na CA (Palmer, 2001), utilizou-se a Análise de Correspondência Destendencionada (DCA) do programa PCORD (McCune \& Mefford, 1997), para checar se haveria alguma alteração nos resultados, o que novamente não foi observado. Optou-se então por apresentar apenas os resultados da análise CA utilizando a matriz original (com todas as espécies).

As espécies indicadoras dos ambientes de interflúvio e das áreas sujeitas à inundação foram obtidas através do TWINSPAN (Two Way INdicator Species Analysis) desenvolvido por Hill (1979). Para a análise, elaborou-se uma matriz de presença/ausência de espécies nas três áreas de amostragem, utilizada no programa TWINSPAN do pacote PC-ORD (McCune \& Mefford, 1997).
Com base na tabela resultante do TWINSPAN, criou-se um sistema de pesos que manteve as espécies indicadoras fornecidas pelo método mas que, utilizando os valores de importância das espécies em cada ambiente e classe diamétrica, permitiu a subdivisão do grupo de espécies presentes na zona de indiferença, do seguinte modo:

- Valor +2: presente no interflúvio (áreas 1 e/ou 2) e ausente na área inundável (área 3).

- Valor +1: presente ao longo de todo o gradiente de umidade (áreas 1, 2 e 3), mas com destaque em VI somente no interflúvio (áreas 1 e/ou 2).

- Valor -1: presente ao longo de todo o gradiente de umidade (áreas 1, 2 e 3), mas com destaque em VI somente na área inundável (área 3).

- Valor -2 : presente na área inundável (área 3) e ausente no interflúvio (áreas 1 e/ou 2).

- Valor 0: aquelas que não puderam ser incluídas em nenhuma das categorias anteriores.

Quando uma espécie foi registrada nas duas classes diamétricas $(5-10 \mathrm{~cm} \mathrm{e} \geqslant 10 \mathrm{~cm})$, o valor final foi calculado com base na média aritmética dos valores obtidos em cada classe.

Finalmente, considerando-se o valor atribuído a cada espécie, as mesmas foram distribuídas segundo um gradiente de umidade, caracterizado pela posição topográfica na microbacia, que variou de +2 (ambiente não inundável) a -2 (ambiente sazonalmente inundável). Deste modo, foram definidas as seguintes categorias:

- Interflúvio: famílias ou espécies que apresentaram valor +2 (exclusivas), valor +1 (preferenciais) ou valor $+1,5$ ( transição).

- Indiferentes ao regime de inundação: famílias ou espécies que apresentaram valor 0 (típicas) ou valores $\pm 0,5$ (transição).

- Área inundável: famílias ou espécies que apresentaram valor - 2 (exclusivas) ou valor - 1 (preferenciais).

Como exclusivas foram denominadas as espécies que só ocorreram num determinado ambiente (interflúvio ou inundável).

As preferenciais podem ocorrer em mais de um ambiente, mas só assumem altos valores de importância num ambiente específico.

Como indiferentes típicas foram consideradas aquelas espécies que apresentaram valor 0 , ou nos casos em que os valores obtidos em cada classe diamétrica tiveram sinais opostos e que, na média aritmética, resultaram no valor 0 .

Aquelas que não seguem um padrão definido, oscilando entre uma categoria e a vizinha de acordo com a classe diamétrica, foram consideradas espécies de transição.

\section{RESULTADOS}

A flora arbórea inventariada nos 3 ha resultou em 47 famílias, 88 gêneros e 134 espécies (Tabela 1). A densidade média de indivíduos no estrato superior (indivíduos $\geqslant 10 \mathrm{~cm}$ de 


\section{ACTA \\ AMAZONICA}

Tabela 1 - Espécies amostradas em 3ha de floresta em Gaúcha do Norte-MT.

\begin{tabular}{|c|c|c|c|c|c|c|}
\hline & \multirow[t]{2}{*}{ Nome Científico } & \multicolumn{3}{|c|}{ Número de Indivíduos/ha } & \multirow{2}{*}{$\begin{array}{c}\text { Total } \\
\text { 3ha }\end{array}$} & \\
\hline & & Área1 & Área2 & Área3 & & \\
\hline & 1. ANACARDIACEAE & & & & & \\
\hline 1 & Tapirira guianensis Aubl. & 9 & 12 & 1 & 22 & $\mathrm{i}$ \\
\hline \multirow[t]{3}{*}{2} & Thyrsodium spruceanum Benth. & 2 & 19 & 0 & 21 & $\mathrm{i}$ \\
\hline & & 11 & 31 & 1 & 43 & \\
\hline & 2. ANNONACEAE & & & & & \\
\hline 3 & Duguetia marcgraviana Mart. & 0 & 10 & 100 & 110 & $\mathrm{a}$ \\
\hline 4 & Guatteria cf. foliosa Benth. & 33 & 1 & 0 & 34 & $\mathrm{a}$ \\
\hline 5 & Guatteria cf. schomburgkiana Mart. & 24 & 1 & 1 & 26 & $\mathrm{i}$ \\
\hline 6 & Guatteriopsis blepharophylla (Mart.) R.E.Fr. & 22 & 0 & 0 & 22 & $\mathrm{i}$ \\
\hline 7 & Rollinia exsucca A.DC. & 0 & 1 & 0 & 1 & $\mathrm{r}$ \\
\hline 8 & Unonopsis lindmanii R.E.Fr. & 0 & 0 & 6 & 6 & $\mathrm{i}$ \\
\hline 9 & Xylopia amazonica R.E.Fr. & 27 & 8 & 36 & 71 & a \\
\hline 10 & Xylopia cf. ulei Diels & 2 & 38 & 36 & 76 & $\mathrm{a}$ \\
\hline \multirow[t]{2}{*}{11} & Xylopia frutescens Aubl. & 11 & 0 & 0 & 11 & $\mathrm{i}$ \\
\hline & & 119 & 59 & 179 & 357 & \\
\hline
\end{tabular}

\section{APOCYNACEAE}

12 Aspidosperma araracanga Marc.-Ferr.

13 Aspidosperma cf. desmanthum Benth. ex Müll.Arg.

14 Aspidosperma discolor A.DC.

15 Himatanthus sucuuba (Spruce ex Müll.Arg.) Woodson

\begin{tabular}{ccccc}
0 & 3 & 8 & 11 & $\mathrm{i}$ \\
0 & 8 & 0 & 8 & $\mathrm{i}$ \\
14 & 3 & 3 & 20 & $\mathrm{i}$ \\
1 & 5 & 4 & 10 & $\mathrm{i}$ \\
15 & 19 & 15 & 49 & \\
\hline
\end{tabular}

\section{ARALIACEAE}

16 Schefflera morototoni (Aubl.) Maguire, Steyerm. \& Frodin

$\begin{array}{lllll}0 & 2 & 0 & 2 & r \\ 0 & 2 & 0 & 2\end{array}$

\section{ARECAEAE}



\section{BIGNONIACEAE}

18 Jacaranda copaia (Aubl.) D.Don

$\begin{array}{lllll}21 & 10 & 0 & 31 & \mathrm{a}\end{array}$

19 Tabebuia serratifolia G. Nicholson

$\begin{array}{lllll}0 & 1 & 4 & 5 & \mathrm{i}\end{array}$

\section{BOMBACACEAE}

\begin{tabular}{llllllll}
\hline $20 \quad$ Eriotheca $\mathrm{sp}$ & 0 & 0 & 3 & 3 & $\mathrm{r}$ \\
& 0 & 0 & 3 & 3 &
\end{tabular}

\section{BORAGINACEAE}

21 Cordia aff. nervosa Lam.

$\begin{array}{lllll}0 & 2 & 1 & 3 & r \\ 0 & 0 & 1 & 1 & r \\ 0 & 2 & 2 & 4 & \end{array}$

22 Cordia sellowiana Cham. 


\section{ACTA \\ AMAZONICA}

continuação da Tabela 1

\begin{tabular}{|c|c|c|c|c|c|c|}
\hline & \multirow[t]{2}{*}{ Nome Científico } & \multicolumn{3}{|c|}{ Número de Indivíduos/ha } & \multirow{2}{*}{$\begin{array}{c}\text { Total } \\
\text { 3hal }\end{array}$} & \\
\hline & & Área 1 & Área2 & Área3 & & \\
\hline & 9. BURSERACEAE & & & & & \\
\hline 23 & Dacryodes cf. nitens Cuatrec. & 9 & 0 & 0 & 9 & $\mathrm{i}$ \\
\hline 24 & Protium heptaphyllum (Aubl.) Marchand & 0 & 0 & 6 & 6 & $\mathrm{i}$ \\
\hline 25 & Protium pilosissimum Engl. & 37 & 111 & 93 & 241 & a \\
\hline 26 & Protium unifoliolatum Engl. & 7 & 28 & 260 & 295 & $\mathrm{a}$ \\
\hline 27 & Trattinnickia cf. boliviana (Swart) Daly & 1 & 0 & 0 & 1 & r \\
\hline 28 & Trattinnickia glaziovii Swart & 29 & 21 & 0 & 50 & $\mathrm{a}$ \\
\hline 29 & Trattinnickia cf. rhoifolia Willd. & 0 & 1 & 0 & 1 & $r$ \\
\hline & & 83 & 161 & 359 & 603 & \\
\hline
\end{tabular}

\section{CAESALPINIACEAE}

\begin{tabular}{llccccc}
\hline 29 & Apuleia leiocarpa (Vogel) J.F.Macbr. & 0 & 2 & 8 & 10 & $\mathrm{i}$ \\
30 & Copaifera langsdorfii Desf. & 1 & 0 & 1 & 2 & $\mathrm{r}$ \\
31 & Hymenaea courbaril L. & 1 & 8 & 14 & 23 & $\mathrm{i}$ \\
32 & Sclerolobium paniculatum Vogel & 2 & 5 & 1 & 8 & $\mathrm{i}$ \\
& & 4 & $\mathbf{1 5}$ & $\mathbf{2 4}$ & $\mathbf{4 3}$ & \\
\hline
\end{tabular}

\begin{tabular}{lllllll}
\hline 11. CECROPIACEAE & & & & & \\
\hline $33 \quad$ Cecropia cf. distachya Huber & 2 & 0 & 2 & 4 & $r$ \\
\hline
\end{tabular}

\begin{tabular}{lllllll}
\hline & 12. CELASTRACEAE & & & & & \\
\hline 33 & Maytenus sp.1 & 1 & 0 & 0 & 1 & $\mathrm{r}$ \\
34 & Maytenus sp.2 & 1 & 0 & 0 & 1 & $\mathrm{r}$ \\
& & 2 & 0 & 0 & 2 & \\
\hline
\end{tabular}

\begin{tabular}{llccccc}
\hline & 13.CHRYSOBALANACEAE & & & & & \\
\hline 35 & Hirtella bullata Benth. & 4 & 1 & 0 & 5 & $\mathrm{i}$ \\
36 & Hirtella racemosa Lam. & 12 & 19 & 50 & 81 & $\mathrm{a}$ \\
38 & Licania blackii Prance & 4 & 5 & 1 & 10 & $\mathrm{i}$ \\
40 & Licania gardneri (Hook.f.) Fritsch. & 0 & 0 & 17 & 17 & $\mathrm{i}$ \\
41 & Licania heteromorpha Benth. & 0 & 6 & 1 & 7 & $\mathrm{i}$ \\
39 & Licania kunthiana Hook.f. & 1 & 4 & 2 & 7 & $\mathrm{i}$ \\
37 & Licania parvifolia Huber & 0 & 0 & 2 & 2 & $\mathrm{r}$ \\
42 & Licania sp. & 0 & 0 & 1 & 1 & $\mathrm{r}$ \\
& & 21 & 35 & 74 & 130 & \\
\hline
\end{tabular}

\begin{tabular}{lllllll}
\hline 14. CLUSIACEAE & & & & & \\
\hline $43 \quad$ Vismia japurensis Reichardt & 3 & 0 & 0 & 3 & $r$ \\
\hline
\end{tabular}

\section{COMBRETACEAE}

\begin{tabular}{lllllll}
\hline 44 & Buchenavia capitata $($ Vahl) Eichler & 0 & 2 & 0 & 2 & $r$ \\
45 & Buchenavia tomentosa Eichler & 0 & 0 & 1 & 1 & $r$
\end{tabular}




\section{ACTA \\ AMAZONICA}

continuação da Tabela 1

\begin{tabular}{|c|c|c|c|c|c|c|}
\hline & \multirow[t]{2}{*}{ Nome Científico } & \multicolumn{3}{|c|}{ Número de Indivíduos/ha } & \multirow{2}{*}{$\begin{array}{c}\text { Total } \\
\text { 3ha }\end{array}$} & \\
\hline & & Área1 & Área2 & Área3 & & \\
\hline & 16. CONNARACEAE & & & & & \\
\hline \multirow[t]{3}{*}{$\overline{46}$} & Connarus perrottetii (DC.) Planch. & 3 & 0 & 0 & 3 & $r$ \\
\hline & & 3 & 0 & 0 & 3 & \\
\hline & 17. ELAEOCARPACEAE & & & & & \\
\hline 47 & Sloanea guianensis (Aubl.) Benth. & 0 & 7 & 3 & 10 & $\mathrm{i}$ \\
\hline \multirow[t]{3}{*}{48} & Sloanea robusta Vittien & 57 & 18 & 25 & 100 & $\mathrm{a}$ \\
\hline & & 57 & 25 & 28 & 110 & \\
\hline & 18. EUPHORBIACEAE & & & & & \\
\hline 49 & Aparisthmium cordatum Baill. & 81 & 1 & 0 & 82 & $\mathrm{a}$ \\
\hline 50 & Chaetocarpus echinocarpus (Baill.) Ducke & 29 & 55 & 6 & 90 & $\mathrm{a}$ \\
\hline 51 & Mabea fistulifera Mart. & 2 & 16 & 0 & 18 & $\mathrm{i}$ \\
\hline 52 & Maprounea guianensis Aubl. & 5 & 1 & 0 & 6 & $\mathrm{i}$ \\
\hline 53 & Pera coccinea (Benth.) Müll.Arg. & 8 & 22 & 1 & 31 & $\mathrm{a}$ \\
\hline 54 & Pera schomburgkiana Müll. Arg. & 0 & 2 & 26 & 28 & $\mathrm{a}$ \\
\hline \multirow[t]{3}{*}{55} & Sapium glandulatum (Vell.) Pax & 0 & 1 & 0 & 1 & $r$ \\
\hline & & 125 & 98 & 33 & 256 & \\
\hline & 19. FABACEAE & & & & & \\
\hline 56 & Diplotropis triloba Gleason & 1 & 1 & 0 & 2 & $r$ \\
\hline \multirow[t]{3}{*}{57} & Ormosia arborea (Vell.) Harms. & 3 & 0 & 2 & 5 & $\mathrm{i}$ \\
\hline & & 4 & 1 & 2 & 7 & \\
\hline & 20. FLACOURTIACEAE & & & & & \\
\hline \multirow[t]{3}{*}{58} & Casearia gossypiosperma Briq. & 0 & 1 & 0 & 1 & $r$ \\
\hline & & 0 & 1 & 0 & 1 & \\
\hline & 21. HIPPOCRATEACEAE & & & & & \\
\hline \multirow[t]{3}{*}{59} & Cheiloclinium cognatum (Miers) A.C.Sm. & 44 & 0 & 0 & 44 & $\mathrm{a}$ \\
\hline & & 44 & 0 & 0 & 44 & \\
\hline & 22. HUMIRIACEAE & & & & & \\
\hline \multirow[t]{3}{*}{60} & Sacoglottis mattogrossensis Malme & 19 & 23 & 1 & 43 & $\mathrm{a}$ \\
\hline & & 19 & 23 & 1 & 43 & \\
\hline & 23. LACISTEMATACEAE & & & & & \\
\hline 61 & Lacistema aggregatum (Bergius) Rusby & 0 & 0 & 7 & 7 & $\mathrm{i}$ \\
\hline \multirow[t]{3}{*}{62} & Lacistema pubescens Mart. & 7 & 0 & 0 & 7 & $\mathrm{i}$ \\
\hline & & 7 & 0 & 7 & 14 & \\
\hline & 24. LAURACEAE & & & & & \\
\hline 63 & Endlicheria sp. & 0 & 0 & 5 & 5 & $\mathrm{i}$ \\
\hline 64 & Nectandra aff. cissiflora Nees & 71 & 46 & 0 & 117 & a \\
\hline 65 & Nectandra cuspidata Nees \& Mart. & 4 & 7 & 0 & 11 & $\mathrm{i}$ \\
\hline 66 & Ocotea cf. glomerata (Nees) Mez & 0 & 65 & 0 & 65 & $\mathrm{a}$ \\
\hline 67 & Ocotea guianensis Aubl. & 75 & 2 & 0 & 77 & $\mathrm{a}$ \\
\hline 68 & Ocotea sp. 1 & 0 & 0 & 2 & 2 & $r$ \\
\hline 69 & Ocotea sp. 2 & 21 & 6 & 0 & 27 & $\mathrm{i}$ \\
\hline \multirow[t]{2}{*}{70} & Ocotea sp. 3 & 0 & 0 & 1 & 1 & $r$ \\
\hline & & 171 & 126 & 7 & 304 & \\
\hline
\end{tabular}


continuação da Tabela 1

\begin{tabular}{|c|c|c|c|c|c|c|}
\hline & \multirow[t]{2}{*}{ Nome Científico } & \multicolumn{3}{|c|}{ Número de Indivíduos/ha } & \multirow{2}{*}{$\begin{array}{c}\text { Total } \\
\text { 3ha }\end{array}$} & \\
\hline & & Área 1 & Área2 & Área3 & & \\
\hline & 25. LYTHRACEAE & & & & & \\
\hline \multirow[t]{3}{*}{71} & Physocalymma scaberrimum Pohl & 0 & 10 & 1 & 11 & $i$ \\
\hline & & 0 & 10 & 1 & 11 & \\
\hline & 26. MALPIGHIACEAE & & & & & \\
\hline 72 & Byrsonima crispa A.Juss. & 1 & 0 & 0 & 1 & $r$ \\
\hline \multirow[t]{3}{*}{73} & Byrsonima cf. laxiflora Griseb. & 0 & 1 & 0 & 1 & $r$ \\
\hline & & 1 & 1 & 0 & 2 & \\
\hline & 27. MELASTOMATACEAE & & & & & \\
\hline 74 & Bellucia grossularioides (L.)Triana & 16 & 4 & 0 & 20 & $\mathrm{i}$ \\
\hline 75 & Miconia cuspidata Naudin & 36 & 0 & 0 & 36 & $\mathrm{a}$ \\
\hline 76 & Miconia dispar Benth. & 6 & 2 & 0 & 8 & $\mathrm{i}$ \\
\hline 77 & Miconia cf. elaeagnoides Cogn. & 24 & 1 & 0 & 25 & $\mathrm{i}$ \\
\hline 78 & Miconia holosericea (L.)DC. & 12 & 0 & 1 & 13 & $\mathrm{i}$ \\
\hline 79 & Miconia cf. tetrasperma Gleason & 5 & 0 & 0 & 5 & $\mathrm{i}$ \\
\hline 80 & Miconia tomentosa (Rich.) D.Don. & 0 & 0 & 8 & 8 & $\mathrm{i}$ \\
\hline 81 & Miconia cf. pyrifolia Naudin & 92 & 2 & 0 & 94 & $\mathrm{a}$ \\
\hline 82 & Miconia splendens (Sw.) Griseb. & 0 & 0 & 14 & 14 & $\mathrm{i}$ \\
\hline 83 & Miconia cf. woytkowskii Wurdack & 0 & 2 & 0 & 2 & $r$ \\
\hline 84 & Miconia sp. & 1 & 0 & 0 & 1 & $r$ \\
\hline 85 & Mouriri acutiflora Naud. & 0 & 0 & 1 & 1 & $r$ \\
\hline \multirow[t]{2}{*}{86} & Mouriri apiranga Spruce ex Triana & 0 & 2 & 3 & 5 & $\mathrm{i}$ \\
\hline & & 192 & 13 & 27 & 232 & \\
\hline
\end{tabular}

\section{MELIACEAE}

\begin{tabular}{lllllll}
\hline 87 & Guarea macrophylla Vahl & 0 & 0 & 5 & 5 & $\mathrm{i}$ \\
88 & Trichilia micrantha Benth. & 2 & 7 & 0 & 9 & $\mathrm{i}$ \\
& & 2 & 7 & 5 & 14 &
\end{tabular}

\begin{tabular}{|c|c|c|c|c|c|c|}
\hline & 29. MENISPERMACEAE & & & & & \\
\hline \multirow[t]{3}{*}{89} & Abuta concolor Poepp. \& Endl. & 0 & 1 & 0 & 1 & $r$ \\
\hline & & 0 & 1 & 0 & 1 & \\
\hline & 30. MIMOSACEAE & & & & & \\
\hline 90 & Abarema jupunba (Willd.) Britton \& Killip & 0 & 0 & 2 & 2 & $r$ \\
\hline 91 & Enterolobium schomburgkii Benth. & 0 & 2 & 0 & 2 & $r$ \\
\hline 92 & Inga heterophylla Willd. & 5 & 2 & 0 & 7 & $\mathrm{i}$ \\
\hline 93 & Inga laurina Willd. & 3 & 1 & 0 & 4 & $\mathrm{r}$ \\
\hline 94 & Inga thibaudiana DC. & 4 & 0 & 0 & 4 & $r$ \\
\hline \multirow[t]{3}{*}{95} & Zygia cataractae (Kunth) L. Rico & 0 & 0 & 81 & 81 & $\mathrm{a}$ \\
\hline & & 12 & 5 & 83 & 100 & \\
\hline & 31. MONIMIACEAE & & & & & \\
\hline \multirow[t]{2}{*}{96} & Siparuna guianensis Aubl. & 3 & 0 & 0 & 3 & $r$ \\
\hline & & 3 & 0 & 0 & 3 & \\
\hline
\end{tabular}




\section{ACTA \\ AMAZONICA}

continuação da Tabela 1

\begin{tabular}{|c|c|c|c|c|c|c|}
\hline & \multirow[t]{2}{*}{ Nome Científico } & \multicolumn{3}{|c|}{ Número de Indivíduos/ha } & \multirow{2}{*}{$\begin{array}{c}\text { Total } \\
\text { 3ha }\end{array}$} & \\
\hline & & Área1 & Área2 & Área3 & & \\
\hline & 32. MORACEAE & & & & & \\
\hline 97 & Ficus catappifolia Kunth. \& Bouché & 0 & 0 & 2 & 2 & $\mathrm{r}$ \\
\hline 98 & Maclura tinctoria (L.) Engl. & 0 & 2 & 1 & 3 & $r$ \\
\hline 99 & Perebea cf. longepedunculata C.C.Berg & 0 & 0 & 1 & 1 & $r$ \\
\hline 100 & Pseudolmedia laevigata Trécul & 0 & 0 & 65 & 65 & a \\
\hline 101 & Pseudolmedia macrophylla Trécul & 16 & 20 & 0 & 36 & a \\
\hline \multirow[t]{3}{*}{102} & Sorocea klotzchiana Baill. & 0 & 0 & 39 & 39 & $\mathrm{a}$ \\
\hline & & 16 & 22 & 108 & 146 & \\
\hline & 33. MYRISTICACEAE & & & & & \\
\hline 103 & Iryanthera cf. laevis Markgr. & 0 & 0 & 2 & 2 & $r$ \\
\hline \multirow[t]{3}{*}{104} & Virola sebifera Aubl. & 4 & 4 & 1 & 9 & $\mathrm{i}$ \\
\hline & & 4 & 4 & 3 & 11 & \\
\hline & 34. MYRTACEAE & & & & & \\
\hline 105 & Campomanesia sp & 1 & 0 & 1 & 2 & $r$ \\
\hline 106 & Eugenia florida DC. & 0 & 9 & 9 & 18 & $\mathrm{i}$ \\
\hline 107 & Myrcia amazonica DC. & 0 & 56 & 55 & 111 & a \\
\hline 108 & Myrcia fallax (Rich.) DC. & 3 & 3 & 0 & 6 & $\mathrm{i}$ \\
\hline 109 & Myrciaria dubia (Kunth) McVaugh & 5 & 203 & 37 & 245 & $\mathrm{a}$ \\
\hline 110 & Myrciaria sp. & 0 & 6 & 0 & 6 & $\mathrm{i}$ \\
\hline \multirow[t]{2}{*}{111} & Myrtaceae & 0 & 0 & 1 & 1 & $r$ \\
\hline & & 9 & 277 & 103 & 389 & \\
\hline
\end{tabular}

\section{OCHNACEAE}

\begin{tabular}{lllllll}
\hline 112 Ouratea discophora Ducke & 29 & 0 & 73 & 102 & a \\
& 29 & 0 & 73 & 102 &
\end{tabular}

\section{OLACACEAE}

113 Dulacia inopiflora (Miers) Kuntze

114 Heisteria ovata (L.) Engl.

115 Minquartia guianensis Aubl.

\begin{tabular}{lllll}
2 & 0 & 0 & 2 & $r$ \\
0 & 0 & 1 & 1 & $r$ \\
1 & 1 & 1 & 3 & \\
3 & 1 & 2 & 6 & \\
\hline
\end{tabular}

\section{OPILIACEAE}

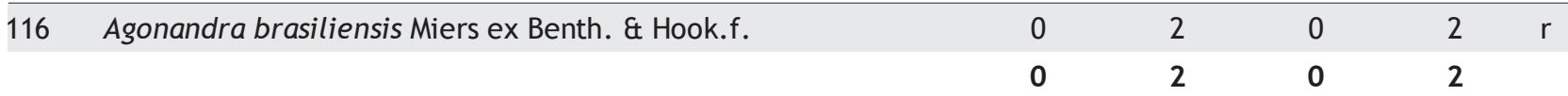

\section{POLYGONACEAE}

117 Triplaris americana $\mathrm{L}$.

$\begin{array}{lllll}0 & 1 & 2 & 3 & r \\ 0 & 1 & 2 & 3 & \end{array}$

\section{QUIINACEAE}

118 Quiina sp.1

119 Quiina sp.2

$\begin{array}{lllcl}0 & 0 & 5 & 5 & \mathrm{i} \\ 0 & 5 & 0 & 5 & \mathrm{i} \\ 0 & 5 & 5 & 10 & \end{array}$


continuação da Tabela 1

\begin{tabular}{|c|c|c|c|c|c|c|}
\hline & \multirow{2}{*}{ Nome Científico } & \multicolumn{3}{|c|}{ Número de Indivíduos/ha } & \multirow{2}{*}{$\begin{array}{l}\text { Total } \\
\text { 3hat }\end{array}$} & \\
\hline & & Área1 & Área2 & Área3 & & \\
\hline & 40. RUBIACEAE & & & & & \\
\hline 120 & Alibertia edulis (Rich.) A. Rich. ex DC. & 4 & 0 & 1 & 5 & $i$ \\
\hline 121 & Amaioua guianensis Aubl. & 106 & 176 & 55 & 337 & $a$ \\
\hline 122 & Coussarea hydrangeifolia (Benth.) Müll.Arg. & 0 & 0 & 1 & 1 & $r$ \\
\hline \multirow[t]{3}{*}{123} & Palicourea guianensis Aubl. & 1 & 0 & 0 & 1 & $r$ \\
\hline & & 111 & 176 & 57 & 344 & \\
\hline & 41. SAPINDACEAE & & & & & \\
\hline 124 & Cupania cf. scrobiculata Rich. & 4 & 62 & 9 & 75 & a \\
\hline \multirow[t]{2}{*}{125} & Matayba arborescens (Aubl.) Radlk. & 12 & 15 & 6 & 33 & $\mathrm{a}$ \\
\hline & & 16 & 77 & 15 & 108 & \\
\hline
\end{tabular}

42. SAPOTACEAE

\begin{tabular}{llccccc}
\hline 126 & Micropholis venulosa (Mart. \& Eichler) Pierre & 3 & 0 & 0 & 3 & $r$ \\
127 & Micropholis sp & 0 & 0 & 10 & 10 & $i$ \\
128 & Pouteria gardneri (Mart. \& Miq.) Baehni & 2 & 4 & 8 & 14 & $i$ \\
129 & Pouteria torta (Mart.) Radlk. & 0 & 2 & 0 & 2 & $r$ \\
& & 5 & 6 & $\mathbf{1 8}$ & $\mathbf{2 9}$ &
\end{tabular}

43. SIMAROUBACEAE

\begin{tabular}{|c|c|c|c|c|c|c|}
\hline \multirow[t]{2}{*}{130} & Simarouba amara Aubl. & 1 & 0 & 1 & 2 & $r$ \\
\hline & & 1 & 0 & 1 & 2 & \\
\hline & 44. STERCULIACEAE & & & & & \\
\hline \multirow[t]{3}{*}{131} & Guazuma ulmifolia Lam. & 0 & 1 & 0 & 1 & $r$ \\
\hline & & 0 & 1 & 0 & 1 & \\
\hline & 45. TILIACEAE & & & & & \\
\hline \multirow[t]{3}{*}{132} & Mollia lepidota Spruce ex Benth. & 0 & 5 & 0 & 5 & $\mathrm{i}$ \\
\hline & & 0 & 5 & 0 & 5 & \\
\hline & 46. ULMACEAE & & & & & \\
\hline \multirow[t]{3}{*}{133} & Trema micrantha (L.) Blume & 0 & 2 & 0 & 2 & $r$ \\
\hline & & 0 & 2 & 0 & 2 & \\
\hline & 47. VOCHYSIACEAE & & & & & \\
\hline \multirow[t]{2}{*}{134} & Vochysia ferruginea Mart. & 6 & 0 & 1 & 7 & $\mathrm{i}$ \\
\hline & & 6 & 0 & 1 & 7 & \\
\hline
\end{tabular}

Área 1- Floresta no interflúvio da margem direita do Rio Pacuneiro; Área 2 - Floresta no interflúvio da margem esquerda do Rio Pacuneiro; Área 3 - Floresta na margem do Rio Pacuneiro. Em negrito estão os totais de indivíduos por família.

$r$ - Espécies raras (até 1 ind/ha); i - Espécies intermediárias ( até 9 ind/ha); a - Espécies abundantes (mais de 10 ind/ha).

diâmetro) foi de 546 ind./ha e a área basal média de $21 \mathrm{~m}^{2} /$ ha. No estrato inferior (5-9,9 $\mathrm{cm}$ de diâmetro) a densidade média foi de 654 ind./ha e a área basal média de $7 \mathrm{~m}^{2} /$ ha (Tabela 2).

Os componentes do estrato inferior foram árvores de pequeno diâmetro e baixa altura (diâmetro inferior a $10 \mathrm{~cm}$ e até $10 \mathrm{~m}$ de altura, Figura 2). No estrato superior foram amostradas árvores de $10-40 \mathrm{~cm}$ diâmetro e $10-20 \mathrm{~m}$ de altura, que formavam um dossel irregular, e também algumas árvores emergentes, que apresentaram diâmetro elevado $(40-140 \mathrm{~cm})$ e mais de $20 \mathrm{~m}$ de altura (Figura 2 ).

A distribuição do número de indivíduos vivos por classe de diâmetro tendeu a seguir uma função exponencial negativa (J invertido), com muitos indivíduos de pequeno diâmetro e poucos indivíduos de diâmetro elevado (Figura 



Figura 2 - Altura e diâmetro dos indivíduos amostrados no interflúvio (áreas 1 e 2) e na margem do Rio Pacuneiro (área 3), em Gaúcha do Norte-MT.

3). Apenas as espécies Thyrsodium spruceanum Benth., Hymenaea courbaril L., Sloanea guianensis (Aubl.) Benth., Aspidosperma cf. desmantbum Benth. ex Müll. Arg.,
Aspidosperma discolor A. DC. e Pseudolmedia laevigata Trécul atingiram diâmetros superiores a $80 \mathrm{~cm}$. Os indivíduos mortos também seguiram a mesma função, evidenciando que as florestas analisadas não sofreram impactos severos na última década, como cortes rasos ou grandes incêndios (Swaine et al., 1987; Richards, 1996).

De maneira geral, as florestas analisadas na microbacia do rio Pacuneiro apresentaram valores de área basal muito inferiores (18,63 a 23,95 $\mathrm{m}^{2}$ - Tabela 2) àqueles registrados para as florestas de terra firme na Amazônia, que apresentam

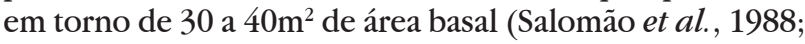
Pitman et al., 2001).

Os trechos florestais amostrados nas áreas 2 e 3 apresentaram densidade semelhantes para diâmetros maiores ou iguais a $10 \mathrm{~cm}$ (Tabela 2), apesar do número de indivíduos mortos ter sido mais elevado na área 2. Mesmo com densidades semelhantes, a área 3 apresentou maior área basal, o que significa que a floresta na margem do rio Pacuneiro apresentou indivíduos com maior diâmetro que a floresta dos interflúvios. Já a área 1, presente no interflúvio da margem direita do Pacuneiro, apresentou menor número de indivíduos e elevada mortalidade nas primeiras classes diamétricas (Figura 3).

As famílias de baixa riqueza específica ( 1 ou 2 espécies - Tabela 3) concentraram 34\% do total de espécies, com predomínio daquelas de baixa densidade (61\% das espécies destas famílias foram consideradas raras). Já as famílias de elevada riqueza específica, ao concentrar espécies das três categorias (baixa, intermediária e alta densidade), acabaram por destacar-se entre aquelas com maior número de indivíduos da comunidade.

Com relação ao valor de importância, as famílias de maior destaque nos três hectares analisados não foram as mesmas (Tabelas 4 e 5), revelando diferenças estruturais entre as áreas.

Tabela 2 - Área basal, densidade, número de espécies, gêneros e famílias, índice de diversidade e eqüabilidade em três hectares de florestas em Gaúcha do Norte-MT.

\begin{tabular}{lcccccccccc}
\hline \hline Local & $\begin{array}{c}\text { Diam } \\
\mathrm{cm}\end{array}$ & $\begin{array}{c}\mathrm{AB} \\
\mathrm{m}^{2} / \mathrm{ha}\end{array}$ & $\begin{array}{c}\mathrm{DE} \\
\text { ind/ha }\end{array}$ & $\begin{array}{c}\text { Mortas } \\
\text { ind/ha }\end{array}$ & $\begin{array}{c}\text { Famílias } \\
\mathrm{n}^{\circ}\end{array}$ & $\begin{array}{c}\text { Gêneros } \\
\mathrm{n}^{\circ}\end{array}$ & $\begin{array}{c}\text { Espécies } \\
\mathrm{n}^{\circ}\end{array}$ & $\mathrm{H}^{\circ}$ & Eq & QMJ \\
\hline Área 1 & $\geqslant 10$ & 18,63 & 588 & 83 & 28 & 42 & 51 & 3,26 & 0,83 & $1: 12$ \\
(1ha) & $5-9,9$ & 1,86 & 534 & 59 & 30 & 49 & 63 & 3,50 & 0,85 & $1: 8$ \\
Área 2 & $\geqslant 10$ & 20,56 & 536 & 67 & 32 & 52 & 66 & 3,30 & 0,79 & $1: 8$ \\
(1ha) & $5-9,9$ & 2,48 & 695 & 35 & 27 & 43 & 58 & 2,93 & 0,72 & $1: 12$ \\
Área 3 & $\geqslant 10$ & 23,95 & 515 & 35 & 27 & 47 & 57 & 3,07 & 0,76 & $1: 9$ \\
(1ha) & $5-9,9$ & 2,65 & 733 & 44 & 28 & 45 & 51 & 2,91 & 0,74 & $1: 14$ \\
Total & $\geqslant 10$ & 21,05 & 546 & 62 & 43 & 79 & 110 & 3,86 & 0,82 & $1: 15$ \\
(3ha) & $5-9,9$ & 6,99 & 654 & 46 & 39 & 75 & 111 & 3,62 & 0,77 & $1: 18$ \\
\hline \hline
\end{tabular}

Área 1 - Floresta no interflúvio da margem direita do Rio Pacuneiro; Área 2 - Floresta no interflúvio da margem esquerda do Rio Pacuneiro; Área 3 - Floresta na margem do Rio Pacuneiro; Diam - diâmetro de inclusão a 1,30cm; AB - Área basal; DE - densidade; H' - Índice de diversidade de Shannon, Eq -

Equabilidade, Q MJ - Quociente de mistura de Jentsch. 
Tabela 3 - Famílias amostradas em 3ha de floresta em Gaúcha do Norte-MT.

\begin{tabular}{|c|c|c|c|c|c|c|c|c|c|}
\hline \multirow[t]{2}{*}{ Famílias } & \multicolumn{5}{|c|}{ Número de Espécies } & \multicolumn{3}{|c|}{ Número de Indivíduos/ha } & \multirow{2}{*}{$\begin{array}{c}\text { Total } \\
\text { 3ha }\end{array}$} \\
\hline & Total & Cong. & $\mathbf{R}$ & $\mathrm{I}$ & A & Área1 & Área2 & Área3 & \\
\hline Melastomataceae & 13 & $2+10$ & 3 & 8 & 2 & 192 & 13 & 27 & 232 \\
\hline Annonaceae & 9 & $2+3$ & 1 & 4 & 4 & 119 & 59 & 179 & 357 \\
\hline Chrysobalanaceae & 8 & $2+6$ & 2 & 5 & 1 & 21 & 35 & 74 & 130 \\
\hline Lauraceae & 8 & $2+5$ & 2 & 3 & 3 & 171 & 126 & 7 & 304 \\
\hline Burseraceae & 7 & $3+3$ & 2 & 2 & 3 & 83 & 161 & 359 & 603 \\
\hline Euphorbiaceae & 7 & 2 & 1 & 2 & 4 & 125 & 98 & 33 & 256 \\
\hline Myrtaceae & 7 & $2+2$ & 2 & 3 & 2 & 9 & 277 & 103 & 389 \\
\hline Mimosaceae & 6 & 3 & 4 & 1 & 1 & 12 & 5 & 83 & 100 \\
\hline Moraceae & 6 & 2 & 3 & 0 & 3 & 16 & 22 & 108 & 146 \\
\hline Apocynaceae & 4 & 3 & 0 & 4 & 0 & 15 & 19 & 15 & 49 \\
\hline Caesalpiniaceae & 4 & 0 & 1 & 3 & 0 & 4 & 15 & 24 & 43 \\
\hline Rubiaceae & 4 & 0 & 2 & 1 & 1 & 111 & 176 & 57 & 344 \\
\hline Sapotaceae & 4 & $2+2$ & 2 & 2 & 0 & 5 & 6 & 18 & 29 \\
\hline Olacaceae & 3 & 0 & 3 & 0 & 0 & 3 & 1 & 2 & 6 \\
\hline Anacardiaceae & 2 & 0 & 0 & 2 & 0 & 11 & 31 & 1 & 43 \\
\hline Bignoniaceae & 2 & 0 & 0 & 1 & 1 & 21 & 11 & 4 & 36 \\
\hline Boraginaceae & 2 & 2 & 2 & 0 & 0 & 0 & 2 & 2 & 4 \\
\hline Celastraceae & 2 & 2 & 2 & 0 & 0 & 2 & 0 & 0 & 2 \\
\hline Combretaceae & 2 & 0 & 2 & 0 & 0 & 0 & 2 & 1 & 3 \\
\hline Elaeocarpaceae & 2 & 2 & 0 & 1 & 1 & 57 & 25 & 28 & 110 \\
\hline Fabaceae & 2 & 0 & 1 & 1 & 0 & 4 & 1 & 2 & 7 \\
\hline Lacistemataceae & 2 & 2 & 0 & 2 & 0 & 7 & 0 & 7 & 14 \\
\hline Malpighiaceae & 2 & 2 & 2 & 0 & 0 & 1 & 1 & 0 & 2 \\
\hline Meliaceae & 2 & 0 & 0 & 2 & 0 & 2 & 7 & 5 & 14 \\
\hline Myristicaceae & 2 & 0 & 1 & 1 & 0 & 4 & 4 & 3 & 11 \\
\hline Quiinaceae & 2 & 2 & 0 & 2 & 0 & 0 & 5 & 5 & 10 \\
\hline Sapindaceae & 2 & 0 & 0 & 0 & 2 & 16 & 77 & 15 & 108 \\
\hline Araliaceae & 1 & 0 & 1 & 0 & 0 & 0 & 2 & 0 & 2 \\
\hline Arecaceae & 1 & 0 & 1 & 0 & 0 & 0 & 1 & 2 & 3 \\
\hline Bombacaceae & 1 & 0 & 1 & 0 & 0 & 0 & 0 & 3 & 3 \\
\hline Cecropiaceae & 1 & 0 & 1 & 0 & 0 & 2 & 0 & 2 & 4 \\
\hline Clusiaceae & 1 & 0 & 1 & 0 & 0 & 3 & 0 & 0 & 3 \\
\hline Connaraceae & 1 & 0 & 1 & 0 & 0 & 3 & 0 & 0 & 3 \\
\hline Flacourtiaceae & 1 & 0 & 1 & 0 & 0 & 0 & 1 & 0 & 1 \\
\hline Hippocrateaceae & 1 & 0 & 0 & 0 & 1 & 44 & 0 & 0 & 44 \\
\hline Humiriaceae & 1 & 0 & 0 & 0 & 1 & 19 & 23 & 1 & 43 \\
\hline Lythraceae & 1 & 0 & 0 & 1 & 0 & 0 & 10 & 1 & 11 \\
\hline Menispermaceae & 1 & 0 & 1 & 0 & 0 & 0 & 1 & 0 & 1 \\
\hline Monimiaceae & 1 & 0 & 1 & 0 & 0 & 3 & 0 & 0 & 3 \\
\hline Ochnaceae & 1 & 0 & 0 & 0 & 1 & 29 & 0 & 73 & 102 \\
\hline Opiliaceae & 1 & 0 & 1 & 0 & 0 & 0 & 2 & 0 & 2 \\
\hline Polygonaceae & 1 & 0 & 1 & 0 & 0 & 0 & 1 & 2 & 3 \\
\hline Simaroubaceae & 1 & 0 & 1 & 0 & 0 & 1 & 0 & 1 & 2 \\
\hline Sterculiaceae & 1 & 0 & 1 & 0 & 0 & 0 & 1 & 0 & 1 \\
\hline Tiliaceae & 1 & 0 & 0 & 1 & 0 & 0 & 5 & 0 & 5 \\
\hline Ulmaceae & 1 & 0 & 1 & 0 & 0 & 0 & 2 & 0 & 2 \\
\hline Vochysiaceae & 1 & 0 & 0 & 1 & 0 & 6 & 0 & 1 & 7 \\
\hline
\end{tabular}




\section{ACTA AMAZONICA}

continuação da Tabela 3

\begin{tabular}{lccccccccc}
\hline \hline Famílias & \multicolumn{4}{c}{ Número de Espécies } & \multicolumn{4}{c}{ Número de Indivíduos/ha } & Total \\
\cline { 2 - 10 } & Total & Cong. & R & I & A & Área1 & Área2 & Área3 & 3 ha \\
\hline Opiliaceae & 1 & 0 & 1 & 0 & 0 & 0 & 2 & 0 & 2 \\
Polygonaceae & 1 & 0 & 1 & 0 & 0 & 0 & 1 & 2 & 3 \\
Simaroubaceae & 1 & 0 & 1 & 0 & 0 & 1 & 0 & 1 & 2 \\
Sterculiaceae & 1 & 0 & 1 & 0 & 0 & 0 & 1 & 0 & 1 \\
Tiliaceae & 1 & 0 & 0 & 1 & 0 & 0 & 5 & 0 & 5 \\
Ulmaceae & 1 & 0 & 1 & 0 & 0 & 0 & 2 & 0 & 2 \\
Vochysiaceae & 1 & 0 & 0 & 1 & 0 & 6 & 0 & 1 & 7 \\
\hline \hline
\end{tabular}

Cong. - Espécies congenéricas; R - Espécies raras (até 1 ind/ha); I - Espécies intermediárias ( até 9 ind/ha); A - Espécies abundantes (mais de 10 ind/ha); Área 1- Floresta no interflúvio da margem direita do rio Pacuneiro; Área 2 - Floresta no interflúvio da margem esquerda do rio Pacuneiro; Área 3 - Floresta na margem do rio Pacuneiro.

Nos estratos superiores dos 3ha (Tabela 4) destacou-se Lauraceae, com clara preferência por áreas mais secas, assim como Anacardiaceae e Myrtaceae, que estão entre as famílias de maior importância na área 2, e Melastomataceae na área 1. Já Annonaceae mostrou-se indiferente ao regime de inundação, podendo apresentar altos valores de importância em qualquer posição topográfica. Burseraceae, Moraceae e Caesalpiniaceae assumiram altos valores apenas em áreas inundáveis.

Nos estratos inferiores, o destaque passa a ser praticamente exclusivo das famílias Burseraceae, Myrtaceae e Rubiaceae, que somaram $87 \%$ do valor de importância
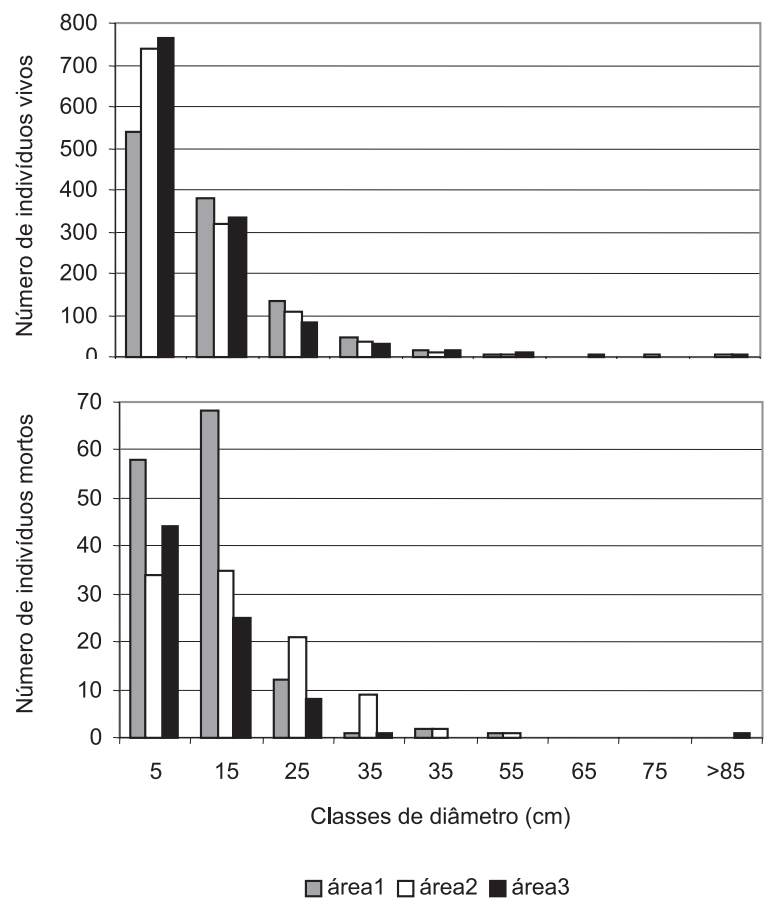

Figura 3 - Distribuição de indivíduos por classe de diâmetro nas florestas de interflúvio (áreas 1 e 2) e na margem do Rio Pacuneiro (área 3), em Gaúcha do Norte-MT. total (Tabela 5). Com relação ao ambiente de ocorrência, Burseraceae destacou-se em áreas inundáveis, Rubiaceae no interflúvio e Myrtaceae mostrou-se indiferente ao regime de inundação.

As espécies de baixa densidade representaram 38,2\% do total de espécies, enquanto as de alta densidade somaram 22,10\% (Tabela 3). As espécies congenéricas representaram mais da metade do total de espécies amostradas (50,3\%).

$\mathrm{O}$ mesmo resultado pode ser constatado para cada área separadamente pela análise da "curva de Lorenz" (Figura 4), que apresenta o grau de desigualdade da distribuição de indivíduos em determinadas espécies por área amostrada. Em termos teóricos, tomando-se um caso extremo, em que todas as espécies apresentassem o mesmo tamanho de população, a curva de Lorenz seria representada pela reta de $45^{\circ}$. Já o grau de convexidade da curva em relação à reta indica o grau de desigualdade na distribuição de indivíduos entre as espécies para as três áreas amostradas. Nos trechos florestais avaliados houve a formação de curvas porque praticamente $80 \%$ das espécies ocorreram com



Figura 4 - Curva de Lorenz para a distribuição de indivíduos por espécies nas florestas de interflúvio (áreas 1 e 2) e na margem do Rio Pacuneiro (área 3). 
Tabela 4 - Valores de importância das famílias dos estratos superiores (diâmetro $>10 \mathrm{~cm}$ ), presentes em florestas nos interflúvios (áreas 1 e 2), na margem do Rio Pacuneiro (área 3) e na área total (3ha), em ordem decrescente de valor importância na área total.

\begin{tabular}{|c|c|c|c|c|}
\hline Família & Área 1 & Área 2 & Área 3 & Total \\
\hline Lauraceae & 41,29 & 41,88 & 1,32 & 28,16 \\
\hline Annonaceae & 27,61 & 7,93 & 33,62 & 23,05 \\
\hline Burseraceae & 12,29 & 7,09 & 27,75 & 15,71 \\
\hline Caesalpiniaceae & 0,73 & 12,40 & 32,98 & 15,37 \\
\hline Moraceae & 3,97 & 2,62 & 35,41 & 14,00 \\
\hline Euphorbiaceae & 9,86 & 16,79 & 14,41 & 13,68 \\
\hline Rubiaceae & 19,14 & 17,55 & - & 12,23 \\
\hline Melastomataceae & 29,21 & 2,52 & 0,75 & 10,82 \\
\hline Myrtaceae & 1,17 & 26,28 & 4,86 & 10,77 \\
\hline Apocynaceae & 7,71 & 9,79 & 7,93 & 8,48 \\
\hline Anacardiaceae & 0,81 & 24,26 & - & 8,36 \\
\hline Chrysobalanaceae & 8,76 & 3,91 & 10,56 & 7,74 \\
\hline Elaeocarpaceae & 11,74 & 4,73 & 4,53 & 7,00 \\
\hline Mimosaceae & 0,23 & 0,25 & 9,88 & 3,45 \\
\hline Humiriaceae & 7,43 & 1,99 & - & 3,14 \\
\hline Bignoniaceae & 2,65 & 3,50 & 1,59 & 2,58 \\
\hline Ochnaceae & 4,91 & - & 2,60 & 2,50 \\
\hline Sapindaceae & 2,27 & 3,78 & 1,33 & 2,46 \\
\hline Sapotaceae & - & 0,81 & 3,81 & 1,54 \\
\hline Hippocrateaceae & 3,55 & - & - & 1,18 \\
\hline Lythraceae & - & 3,05 & 0,35 & 1,13 \\
\hline Polygonaceae & - & 0,26 & 2,05 & 0,77 \\
\hline Vochysiaceae & 2,29 & - & - & 0,76 \\
\hline Boraginaceae * & - & 1,34 & 0,94 & 0,76 \\
\hline Myristicaceae & - & 1,06 & 1,16 & 0,74 \\
\hline Fabaceae & 0,64 & 0,94 & - & 0,52 \\
\hline Combretaceae * & - & 1,12 & 0,43 & 0,51 \\
\hline Opiliaceae * & - & 1,01 & 0,24 & 0,41 \\
\hline Tiliaceae & - & 1,24 & - & 0,41 \\
\hline Meliaceae & - & 0,46 & 0,74 & 0,40 \\
\hline Cecropiaceae * & 0,51 & - & 0,61 & 0,37 \\
\hline Simaroubaceae * & 0,75 & - & 0,37 & 0,37 \\
\hline Quiinaceae & - & 0,81 & - & 0,27 \\
\hline Malpighiaceae * & 0,31 & 0,31 & - & 0,20 \\
\hline Araliaceae * & - & 0,59 & - & 0,20 \\
\hline Sterculiaceae * & - & 0,49 & - & 0,16 \\
\hline Bombacaceae & - & - & 0,48 & 0,16 \\
\hline Indeterminada * & 0,38 & - & - & 0,13 \\
\hline Arecaceae & - & 0,35 & - & 0,12 \\
\hline Olacaceae & - & - & 0,33 & 0,11 \\
\hline Celastraceae & 0,29 & - & - & 0,10 \\
\hline Connaraceae & 0,28 & - & - & 0,09 \\
\hline Clusiaceae & 0,23 & - & - & 0,08 \\
\hline
\end{tabular}

* Famílias registradas apenas nessa classe diamétrica densidade baixa ou intermediária, totalizando aproximadamente $10 \%$ dos indivíduos amostrados, principalmente na área 2, que apresentou maior número de espécies raras. Consequentemente, apenas cerca de $20 \%$ das espécies concentraram os $90 \%$ de indivíduos restantes, demonstrando que há uma pequena proporção de espécies que ocorrem com alta densidade local. Ou seja, o tamanho das populações é bastante desigual.

Duas áreas podem ser consideradas florísticamente semelhantes quando o índice de Jaccard é superior a 25\% (Mueller-Dombois \& Ellemberg, 1974). Nesse contexto, as três áreas apresentaram-se muito semelhantes, com mais de $27 \%$ de similaridade no índice de Jaccard e acima de $30 \%$ no índice de Sørensen (Tabela 6). Os estratos superiores das florestas presentes no interflúvio mostraram maior semelhança entre si do que com a floresta na margem do rio Pacuneiro, mas no estrato inferior as florestas de interflúvio apresentaram baixa similaridade entre si e índices mais elevados com a floresta inundável (área 3).


Figura 5 - Ordenação das espécies e áreas de amostragem pela Análise de Correspondência, utilizando como variável a densidade absoluta das espécies em cada local (1 e 2 são áreas de interflúvio e a área 3 na margem do Rio Pacuneiro). O gráfico A apresenta a ordenação para as espécies do estrato superior e o gráfico B para o estrato inferior. Nem todas as espécies podem ser visualizadas no gráfico, porque há sobreposição de pontos. Os valores percentuais indicam a variância acumulada em cada eixo. 


\section{ACTA AMAZONICA}

Tabela 5 - Valores de importância das famílias dos estratos inferiores (diâmetro $<10 \mathrm{~cm}$ ), presentes em florestas nos interflúvios (áreas 1 e 2), na margem do Rio Pacuneiro (área 3) e na área total (3ha), ordenadas em ordem decrescente de valor de importância na área total.

\begin{tabular}{|c|c|c|c|c|}
\hline Família & Área 1 & Área 2 & Área 3 & Total \\
\hline Burseraceae & 18,47 & 38,93 & 68,46 & 41,95 \\
\hline Myrtaceae & 1,67 & 51,15 & 21,77 & 24,86 \\
\hline Rubiaceae & 16,00 & 31,23 & 12,97 & 20,06 \\
\hline Euphorbiaceae & 32,14 & 13,20 & 1,85 & 15,73 \\
\hline Annonaceae & 15,36 & 9,53 & 19,00 & 14,63 \\
\hline Melastomataceae & 35,05 & 2,17 & 6,56 & 14,59 \\
\hline Lauraceae & 27,77 & 6,79 & 0,77 & 11,78 \\
\hline Sapindaceae & 3,67 & 17,45 & 2,47 & 7,87 \\
\hline Ochnaceae & 4,36 & - & 15,93 & 6,76 \\
\hline Moraceae & 1,74 & 3,29 & 13,71 & 6,24 \\
\hline Chrysobalanaceae & 0,66 & 6,20 & 11,05 & 5,97 \\
\hline Mimosaceae & 3,98 & 1,01 & 11,86 & 5,62 \\
\hline Elaeocarpaceae & 7,06 & 4,72 & 3,54 & 5,11 \\
\hline Hippocrateaceae & 11,65 & - & - & 3,88 \\
\hline Sapotaceae & 2,13 & 1,39 & 2,52 & 2,02 \\
\hline Humiriaceae & 0,87 & 4,60 & 0,36 & 1,94 \\
\hline Bignoniaceae & 4,38 & 0,99 & 0,28 & 1,88 \\
\hline Anacardiaceae & 3,07 & 1,50 & 0,31 & 1,63 \\
\hline Lacistemataceae * & 2,07 & - & 1,82 & 1,30 \\
\hline Meliaceae & 0,85 & 1,52 & 0,50 & 0,95 \\
\hline Quiinaceae & - & 0,94 & 1,46 & 0,80 \\
\hline Caesalpiniaceae & 0,63 & 0,87 & 0,73 & 0,74 \\
\hline Myristicaceae & 1,59 & 0,62 & - & 0,73 \\
\hline Olacaceae & 1,19 & 0,36 & 0,24 & 0,60 \\
\hline Apocynaceae & 0,66 & 0,48 & 0,49 & 0,55 \\
\hline Monimiaceae * & 1,16 & - & - & 0,39 \\
\hline Fabaceae & 0,65 & - & 0,51 & 0,39 \\
\hline Connaraceae & 0,78 & - & - & 0,26 \\
\hline Arecaceae & - & - & 0,69 & 0,23 \\
\hline Lythraceae & - & 0,64 & - & 0,21 \\
\hline Bombacaceae & - & - & 0,61 & 0,20 \\
\hline Vochysiaceae & 0,38 & - & 0,23 & 0,20 \\
\hline Clusiaceae & 0,60 & - & - & 0,20 \\
\hline Ulmaceae * & - & 0,52 & - & 0,17 \\
\hline Celastraceae & 0,42 & - & - & 0,14 \\
\hline Tiliaceae & - & 0,35 & - & 0,12 \\
\hline Flacourtiaceae * & - & 0,33 & - & 0,11 \\
\hline Polygonaceae & - & - & 0,32 & 0,11 \\
\hline Menispermaceae * & - & 0,26 & - & 0,09 \\
\hline
\end{tabular}

* Famílias registradas apenas nessa classe diamétrica
As pequenas diferenças na composição florística, constatadas pelos índices de similaridade, também foram observadas na comparação estrutural, revelada pela Análise de Correspondência (Figura 5).

Para o estrato superior (Figura 5A), a ordenação das áreas amostrais em relação ao eixo 1 segue o gradiente de umidade, mantendo a área sujeita à inundação no lado negativo (área 3) e as áreas de interflúvio no lado positivo (áreas 1 e 2), com $\mathrm{a}$ área 1 na extremidade do gradiente. Nota-se que existem espécies que ocorrem com maior densidade numa das três áreas, e há aquelas indiferentes, que tendem a ocupar a região central da figura. Mesmo no interflúvio, existem diferenças na composição e densidade das espécies, pois as áreas 1 e 2 foram separadas pelo eixo 2 .

No estrato inferior (Figura 5B), o gradiente de umidade não é o predominante já que, pela análise do eixo 1 , a floresta de interflúvio da margem direita do Rio Pacuneiro (área 1) foi alocada no lado negativo, enquanto o interflúvio da margem esquerda (área 2) e a floresta na margem do rio (área 3) foram alocadas no lado positivo. A separação da área 1 da área 2 indica que, apesar da alta similaridade florística entre ambas para este estrato (Tabela 6), a densidade das espécies de subosque não é a mesma nos dois ambientes.

Muitas espécies apresentaram distribuição não aleatória em relação ao gradiente de umidade, formando blocos florísticos no dendrograma obtido pela análise TWINSPAN (Figura 6): houve a formação de blocos de espécies indicadoras de áreas de interflúvio e de áreas inundáveis, e a presença de blocos de espécies que podem ocorrer numa ou noutra área (indiferentes). A inclusão de pesos baseado no valor de importância de cada espécie em cada área refinou os blocos detectados pelo TWINSPAN, sendo possível indicar

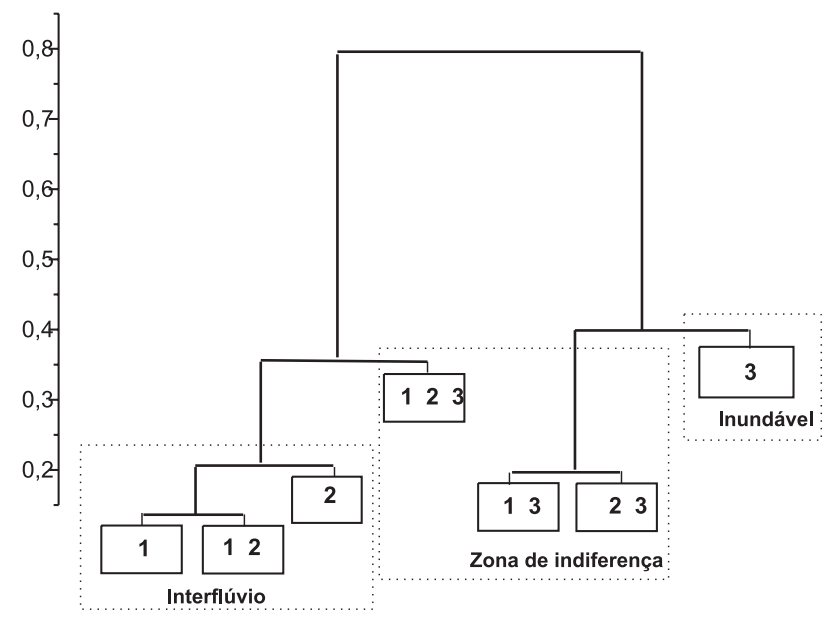

Figura 6 - Dendrograma de similaridade florística obtido pelo TWINSPAN, através da análise de uma matriz de presença/ausência de espécies nas florestas de interflúvio (áreas 1 e 2) e na margem do Rio Pacuneiro (área 3). Cada célula ( $\square$ ) é formada por um conjunto de espécies, e o número indica em que (quais) área(s) este conjunto ocorreu. A linha tracejada destaca os blocos de espécies exclusivas do interflúvio ou da área inundável e aquelas indiferentes. 
Tabela 6 - Índices de similaridade entre os trechos florestais amostrados na microbacia do Rio Pacuneiro, em Gaúcha do Norte-MT.

\begin{tabular}{|c|c|c|c|c|c|}
\hline \multirow{2}{*}{ Estrato } & & \multicolumn{2}{|c|}{ Jaccard(\%) } & \multicolumn{2}{|c|}{ Sorenson(\%) } \\
\hline & & Área 1 & Área 2 & Área 1 & Área 2 \\
\hline Inferior (5-9,9 cm de diâmetro) & Área 2 & 21,51 & & 35,40 & \\
\hline Superior $(\geqslant 10 \mathrm{~cm})$ & Área 2 & 32,95 & & 49,57 & \\
\hline Todos $(\geqslant 5 \mathrm{~cm})$ & Área 2 & 45,45 & & 62,50 & \\
\hline Inferior (5-9,9 cm de diâmetro) & Área 3 & 37,08 & 26,74 & 54,10 & 42,20 \\
\hline Superior $(\geqslant 10 \mathrm{~cm})$ & Área 3 & 18,68 & 32,26 & 31,48 & 48,78 \\
\hline Todos $(\geqslant 5 \mathrm{~cm})$ & Área 3 & 27,69 & 38,75 & 30,25 & 55,86 \\
\hline
\end{tabular}

Área 1 - Floresta no interflúvio da margem direita do Rio Pacuneiro; Área 2 - Floresta no interflúvio da margem esquerda do Rio Pacuneiro; Área 3 - Floresta na margem do Rio Pacuneiro

as espécies exclusivas do interflúvio e as ribeirinhas; aquelas que não demonstram nenhuma correlação óbvia com fatores ambientais, denominadas indiferentes; e ainda aquelas espécies que podem ocorrer em mais de um ambiente em qualquer classe diamétrica, mas que se destacam em importância num ambiente específico, considerado o mais adequado ao seu desenvolvimento (Tabelas 7 e 8).

Com relação à diversidade, o índice de Shannon foi mais elevado nas áreas de maior riqueza florística, localizadas nos interflúvios (Tabela 2). A área 2 apresentou a maior diversidade no estrato superior e a área 1 no estrato inferior.
Os valores de eqüabilidade foram mais altos na área 1, indicando que as espécies locais contribuem de maneira mais uniforme para o índice de diversidade. Nessa área, o denominador do quociente de mistura de Jentsch foi menor no estrato inferior (8) em relação ao estrato superior (12), ao contrário das demais áreas (Tabela 2). Ou seja, na área 1 tornase necessário amostrar 12 indivíduos para encontrarmos uma espécie diferente das já amostradas no estrato superior e apenas 8 indivíduos no estrato inferior. Assim, pode-se concluir que o estrato superior da floresta da área 1 apresenta menos espécies do que o estrato inferior, o que já não ocorreu nas demais áreas, onde o estrato superior foi sempre o de maior diversidade.

Tabela 7 - Valores de importância das espécies dos estratos superiores (diâmetro ${ }^{3} 10 \mathrm{~cm}$ ), presentes em florestas nos interflúvios (áreas 1 e 2), na margem do Rio Pacuneiro (área 3) e na área total (3ha), agrupadas de acordo com o ambiente preferencial.

\begin{tabular}{|c|c|c|c|c|c|c|}
\hline Ambiente & & Espécie & área 1 & área 2 & área 3 & Total \\
\hline \multirow[t]{17}{*}{ Interflúvio } & Exclusivas( 2 ) & Nectandra aff. cissiflora & 36,79 & 13,73 & - & 13,21 \\
\hline & & Ocotea cf. glomerata & - & 38,50 & - & 12,65 \\
\hline & & Miconia cf. pyrifolia & 24,99 & 0,54 & - & 8,76 \\
\hline & & Thyrsodium spruceanum & - & 23,43 & - & 7,67 \\
\hline & & Guatteria cf foliosa & 19,87 & 0,63 & - & 6,78 \\
\hline & & Ocotea guianensis & 13,97 & 1,30 & - & 5,24 \\
\hline & & Trattinnickia glaziovii & 8,87 & 4,72 & - & 4,59 \\
\hline & & Pseudolmedia macrophylla & 6,44 & 3,68 & - & 3,44 \\
\hline & & Jacaranda copaia & 4,45 & 5,00 & - & 3,20 \\
\hline & & Mabea fistulifera & 1,25 & 7,89 & - & 3,03 \\
\hline & & Bellucia grossularioides & 6,15 & 2,70 & - & 3,00 \\
\hline & & Ocotea sp 2 & 5,61 & 2,44 & - & 2,73 \\
\hline & & Aparisthmium cordatum & 7,70 & - & - & 2,72 \\
\hline & & Miconia cuspidata & 7,57 & - & - & 2,68 \\
\hline & & Aspidosperma cf desmanthum & - & 7,44 & - & 2,44 \\
\hline & & Cheiloclinium cognatum & 6,69 & - & - & 2,39 \\
\hline & & Miconia cf. elaeagnoides & 6,26 & - & - & 2,23 \\
\hline
\end{tabular}




\section{ACTA \\ AMAZONICA}

continuação da Tabela 7

\begin{tabular}{|c|c|c|c|c|c|c|}
\hline \multirow{2}{*}{$\begin{array}{l}\text { Ambiente } \\
\text { Interflúvio }\end{array}$} & \multirow[b]{2}{*}{ Exclusivas ( 2 ) } & \multirow{2}{*}{$\begin{array}{l}\text { Espécie } \\
\text { Dacryodes of nitens }\end{array}$} & \multirow{2}{*}{$\begin{array}{c}\text { área } 1 \\
6,28\end{array}$} & \multirow{2}{*}{ área 2} & \multirow{2}{*}{ área 3} & \multirow{2}{*}{$\begin{array}{c}\text { Total } \\
2,04\end{array}$} \\
\hline & & & & & & \\
\hline & & Nectandra cuspidata & 0,45 & 4,26 & - & 1,57 \\
\hline & & Myrciaria sp. & - & 3,91 & - & 1,29 \\
\hline & & Maprounea guianensis & 1,59 & 0,67 & - & 0,78 \\
\hline & & Hirtella bullata & 1,65 & 0,54 & - & 0,75 \\
\hline & & Mollia lepidota & - & 2,23 & - & 0,74 \\
\hline & & Diplotropis triloba * & 0,54 & 1,17 & - & 0,57 \\
\hline & & Myrcia fallax & 1,08 & 0,50 & - & 0,54 \\
\hline & & Buchenavia capitata* & - & 1,61 & - & 0,53 \\
\hline & & Xylopia frutescens & 1,26 & - & - & 0,44 \\
\hline & & Agonandra brasiliensis * & - & 1,50 & - & 0,49 \\
\hline & & Quiina sp 2 & - & 1,30 & - & 0,43 \\
\hline & & Guatteriopsis blepharophylla & 1,14 & - & - & 0,39 \\
\hline & & Schefflera morototoni * & - & 1,08 & - & 0,36 \\
\hline & & Rollinia exsucca * & - & 1,00 & - & 0,33 \\
\hline & & Trichilia micrantha & - & 0,95 & - & 0,32 \\
\hline & & Sapium glandulatum * & - & 0,78 & - & 0,26 \\
\hline & & Guazuma ulmifolia * & - & 0,72 & - & 0,24 \\
\hline & & Indeterminada & 0,59 & - & - & 0,20 \\
\hline & & Byrsonima crispa * & 0,51 & - & - & 0,18 \\
\hline & & Byrsonima cf. laxiflora* & - & 0,54 & - & 0,18 \\
\hline & & Connarus perrottetii & 0,49 & - & - & 0,17 \\
\hline & & Maytenus sp. 1 * & 0,49 & - & - & 0,17 \\
\hline & & Trattinnickia cf. boliviana * & 0,46 & - & - & 0,17 \\
\hline & & Inga heterophylla & 0,44 & - & - & 0,16 \\
\hline & & Vismia japurensis & 0,44 & - & - & 0,16 \\
\hline & & Miconia dispar & - & 0,50 & - & 0,16 \\
\hline & & Inga laurina & - & 0,48 & - & 0,16 \\
\hline & Transição $(1,5)$ & Sacoglottis mattogrossensis & 10,36 & 3,48 & - & 4,62 \\
\hline & & Tapirira guianensis & 1,47 & 6,60 & - & 2,70 \\
\hline & & Pera coccinea & - & 3,81 & - & 1,26 \\
\hline & Preferenciais ( 1 ) & Amaioua guianensis & 27,71 & 25,86 & 3,79 & 19,37 \\
\hline & & Chaetocarpus echinocarpus & 6,02 & 14,92 & 1,11 & 7,41 \\
\hline & & Aspidosperma discolor & 10,18 & 2,28 & 3,73 & 5,39 \\
\hline & & Guatteria cf schomburgkiana & 6,76 & - & 0,53 & 2,55 \\
\hline & & Matayba arborescens & 3,61 & 2,06 & 1,90 & 2,52 \\
\hline & & Sloanea guianensis & - & 4,22 & 1,87 & 1,98 \\
\hline & & Himatanthus sucuuba & - & 3,16 & 2,53 & 1,85 \\
\hline & & Licania blackii & 4,60 & - & 0,53 & 1,63 \\
\hline & & Physocalymma scaberrimum & - & 4,29 & 0,63 & 1,61 \\
\hline & & Vochysia ferruginea & 3,40 & - & - & 1,15 \\
\hline & & Virola sebifera & - & 1,80 & 0,53 & 0,75 \\
\hline & & Licania heteromorpha & - & 0,63 & 0,53 & 0,37 \\
\hline & & Ormosia arborea & 0,51 & - & - & 0,18 \\
\hline & & Mouriri apiranga & - & 0,49 & - & 0,16 \\
\hline
\end{tabular}




\section{ACTA \\ AMAZONICA}

continuação da Tabela 7

\begin{tabular}{|c|c|c|c|c|c|c|}
\hline \multirow{2}{*}{$\begin{array}{l}\text { Ambiente } \\
\text { Indiferentes }\end{array}$} & & Espécie & área 1 & área 2 & área 3 & Total \\
\hline & \multirow[t]{3}{*}{ Transição $(0,5)$} & Sloanea robusta & 18,74 & 3,26 & 6,15 & 9,53 \\
\hline & & Sclerolobium paniculatum & 0,68 & 1,06 & 1,90 & 1,26 \\
\hline & & Licania kunthiana & 0,50 & 0,49 & 1,13 & 0,69 \\
\hline & \multirow[t]{12}{*}{ Típicas (0) } & Myrciaria dubia & 0,95 & 30,99 & 5,40 & 12,20 \\
\hline & & Xylopia cf. ulei & 0,93 & 10,76 & 10,32 & 7,15 \\
\hline & & Protium pilosissimum & 2,71 & 6,93 & 6,76 & 5,35 \\
\hline & & Cupania cf. scrobiculata & - & 5,22 & 0,56 & 1,90 \\
\hline & & Cordia aff nervosa * & - & 1,83 & 0,60 & 0,79 \\
\hline & & Myrcia amazonica & - & 1,43 & 0,75 & 0,71 \\
\hline & & Cecropia cf. distachya * & 0,94 & - & 1,17 & 0,70 \\
\hline & & Maclura tinctoria * & - & 1,18 & 0,62 & 0,59 \\
\hline & & Simarouba amara * & 0,96 & - & 0,65 & 0,52 \\
\hline & & Astrocaryum aculeatum & - & 0,58 & - & 0,19 \\
\hline & & Campomanesia sp. & - & - & 0,57 & 0,18 \\
\hline & & Copaifera langsdorfii & 0,45 & - & - & 0,16 \\
\hline & \multirow[t]{3}{*}{ Transição $(-0,5)$} & Xylopia amazonica & 10,20 & 0,56 & 11,39 & 7,32 \\
\hline & & Ouratea discophora & 8,28 & - & 5,52 & 4,61 \\
\hline & & Eugenia florida & - & 1,49 & 3,36 & 1,53 \\
\hline \multirow[t]{30}{*}{ Inundável } & Preferenciais & Hymenaea courbaril & - & 8,58 & 28,76 & 13,21 \\
\hline & \multirow[t]{9}{*}{$(-1)$} & Protium unifoliolatum & - & 1,45 & 34,81 & 11,45 \\
\hline & & Duguetia marcgraviana & - & 0,96 & 32,20 & 10,64 \\
\hline & & Hirtella racemosa & 6,00 & 5,23 & 9,36 & 6,72 \\
\hline & & Pera schomburgkiana & - & 0,49 & 18,56 & 6,46 \\
\hline & & Apuleia leiocarpa * & - & 5,23 & 8,74 & 4,71 \\
\hline & & Aspidosperma araracanga & - & 1,15 & 5,44 & 2,21 \\
\hline & & Pouteria gardneri & - & 1,30 & 2,33 & 1,16 \\
\hline & & Tabebuia serratifolia & - & - & 2,46 & 0,82 \\
\hline & & Triplaris americana & - & 0,49 & 0,52 & 0,32 \\
\hline & \multirow[t]{20}{*}{ Exclusivas ( -2 ) } & Pseudolmedia laevigata & - & - & 42,56 & 14,70 \\
\hline & & Zygia cataractae & - & - & 14,90 & 4,69 \\
\hline & & Licania gardneri & - & - & 4,50 & 1,45 \\
\hline & & Micropholis sp. & - & - & 3,79 & 1,26 \\
\hline & & Sorocea klotzchiana & - & - & 2,15 & 0,66 \\
\hline & & Guarea macrophylla & - & - & 1,61 & 0,49 \\
\hline & & Endlicheria sp & - & - & 1,57 & 0,48 \\
\hline & & Licania parvifolia * & - & - & 1,47 & 0,48 \\
\hline & & Iryanthera cf laevis * & - & - & 1,19 & 0,40 \\
\hline & & Ocotea sp. $1^{*}$ & - & - & 1,18 & 0,37 \\
\hline & & Protium heptaphyllum & - & - & 1,12 & 0,35 \\
\hline & & Cordia sellowiana * & - & - & 0,88 & 0,30 \\
\hline & & Licania sp. * & - & - & 0,86 & 0,29 \\
\hline & & Mouriri acutiflora* & - & - & 0,78 & 0,25 \\
\hline & & Eriotheca sp. & - & - & 0,76 & 0,25 \\
\hline & & Buchenavia tomentosa * & - & - & 0,71 & 0,23 \\
\hline & & Heisteria ovata * & - & - & 0,61 & 0,19 \\
\hline & & Ficus catappifolia * & - & - & 0,59 & 0,18 \\
\hline & & Abarema jupunba & - & - & 0,53 & 0,16 \\
\hline & & Miconia tomentosa & - & - & 0,52 & 0,16 \\
\hline
\end{tabular}

\footnotetext{
* Espécies registradas apenas nessa classe diamétrica
} 


\section{ACTA \\ AMAZONICA}

Tabela 8 - Valores de importância das espécies dos estratos inferiores (diâmetro $<10 \mathrm{~cm}$ ), presentes em florestas nos interflúvios (áreas 1 e 2), na margem do Rio Pacuneiro (área 3) e na área total (3ha), agrupadas de acordo com o ambiente preferencial.

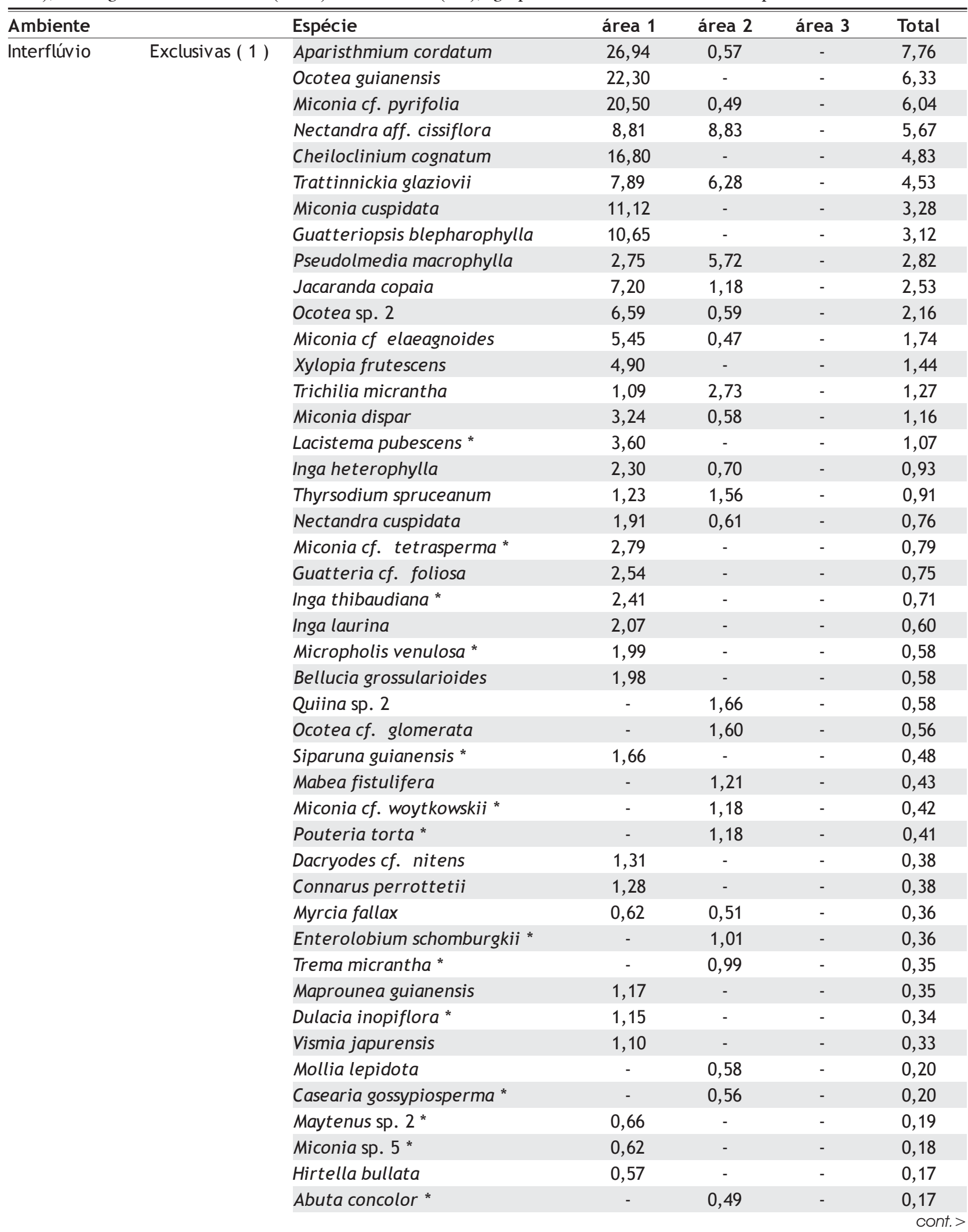




\section{ACTA \\ AMAZONICA}

continuação da Tabela 8

\begin{tabular}{|c|c|c|c|c|c|c|}
\hline Ambiente & & Espécie & área 1 & área 2 & área 3 & Total \\
\hline \multirow[t]{22}{*}{ Interflúvio } & \multirow[t]{4}{*}{ Exclusivas ( 1 ) } & Aspidosperma cf desmanthum & - & 0,48 & - & 0,17 \\
\hline & & Myrciaria sp. & - & 0,47 & - & 0,17 \\
\hline & & Trattinnickia cf. rhoifolia * & - & 0,47 & - & 0,17 \\
\hline & & Palicourea guianensis * & 0,55 & - & - & 0,16 \\
\hline & \multirow[t]{3}{*}{ Transição(1,5) } & Pera coccinea & 4,80 & 7,61 & 0,51 & 4,26 \\
\hline & & Sacoglottis mattogrossensis & 1,37 & 8,01 & 0,61 & 3,43 \\
\hline & & Tapirira guianensis & 3,87 & 1,14 & 0,55 & 1,73 \\
\hline & Preferenciais & Amaioua guianensis & 19,85 & 41,75 & 18,34 & 27,00 \\
\hline & \multirow[t]{14}{*}{$(1)$} & Chaetocarpus echinocarpus & 10,28 & 12,26 & 1,94 & 7,99 \\
\hline & & Matayba arborescens & 3,52 & 5,99 & 1,02 & 3,48 \\
\hline & & Guatteria cf schomburgkiana & 5,02 & 0,47 & - & 1,61 \\
\hline & & Virola sebifera & 2,60 & 1,09 & - & 1,15 \\
\hline & & Licania blackii & - & 2,54 & - & 0,89 \\
\hline & & Licania heteromorpha & - & 2,42 & - & 0,85 \\
\hline & & Mouriri apiranga & - & 1,08 & 1,05 & 0,74 \\
\hline & & Ormosia arborea & 1,15 & - & 1,02 & 0,70 \\
\hline & & Minquartia guianensis * & 0,79 & 0,59 & 0,48 & 0,60 \\
\hline & & Physocalymma scaberrimum & - & 1,11 & - & 0,39 \\
\hline & & Vochysia ferruginea & 0,62 & - & 0,47 & 0,34 \\
\hline & & Sloanea guianensis & - & 1,12 & - & 0,22 \\
\hline & & Himatanthus sucuuba & 0,60 & - & - & 0,18 \\
\hline & & Aspidosperma discolor & 0,56 & - & - & 0,17 \\
\hline \multirow[t]{16}{*}{ Indiferentes } & \multirow[t]{4}{*}{ Transição( 0,5 ) } & Sloanea robusta & 10,40 & 6,28 & 5,39 & 7,14 \\
\hline & & Alibertia edulis * & 2,53 & - & 0,48 & 0,91 \\
\hline & & Sclerolobium paniculatum & 0,57 & 1,34 & - & 0,64 \\
\hline & & Licania kunthiana & - & 1,31 & - & 0,46 \\
\hline & \multirow[t]{9}{*}{ Típicas ( 0 ) } & Protium pilosissimum & 15,95 & 36,97 & 31,16 & 28,89 \\
\hline & & Myrciaria dubia & 1,49 & 45,09 & 12,09 & 20,64 \\
\hline & & Myrcia amazonica & - & 21,51 & 18,88 & 14,36 \\
\hline & & Cupania cf. scrobiculata & 2,45 & 20,98 & 3,56 & 9,37 \\
\hline & & Xylopia cf. ulei & - & 9,00 & 7,63 & 5,86 \\
\hline & & Miconia holosericea * & 6,81 & - & 0,51 & 2,15 \\
\hline & & Astrocaryum aculeatum & - & - & 1,20 & 0,42 \\
\hline & & Copaifera langsdorfii & - & - & 0,62 & 0,22 \\
\hline & & Campomanesia sp. & 0,55 & - & - & 0,16 \\
\hline & \multirow[t]{3}{*}{ Transição(- 0,5) } & Eugenia florida & - & 3,09 & 1,95 & 1,78 \\
\hline & & Ouratea discophora & 6,15 & - & 21,51 & 9,55 \\
\hline & & Xylopia amazonica & 1,74 & 2,74 & 7,38 & 4,08 \\
\hline \multirow[t]{9}{*}{ Inundável } & \multirow{9}{*}{$\begin{array}{l}\text { Preferenciais } \\
(-1)\end{array}$} & Protium unifoliolatum & 4,12 & 11,31 & 58,01 & 26,35 \\
\hline & & Hirtella racemosa & 0,59 & 4,27 & 13,81 & 6,59 \\
\hline & & Duguetia marcgraviana & - & 3,61 & 13,23 & 6,00 \\
\hline & & Pouteria gardneri & 1,41 & 1,17 & 2,06 & 1,55 \\
\hline & & Pera schomburgkiana & - & 0,52 & 1,20 & 0,61 \\
\hline & & Aspidosperma araracanga & - & 0,46 & 1,00 & 0,51 \\
\hline & & Hymenaea courbaril & 0,56 & - & 0,61 & 0,38 \\
\hline & & Tabebuia serratifolia & - & 0,52 & 0,52 & 0,36 \\
\hline & & Triplaris americana & - & - & 0,56 & 0,20 \\
\hline
\end{tabular}




\section{ACTA AMAZONICA}

continuação da Tabela 8

\begin{tabular}{|c|c|c|c|c|c|c|}
\hline \multirow{2}{*}{$\begin{array}{l}\text { Ambiente } \\
\text { Inundável }\end{array}$} & & Espécie & área 1 & área 2 & área 3 & Total \\
\hline & \multirow[t]{19}{*}{ Exclusivas( - 2 ) } & Zygia cataractae & - & - & 17,17 & 6,15 \\
\hline & & Sorocea klotzchiana & - & - & 15,53 & 5,52 \\
\hline & & Pseudolmedia laevigata & - & - & 6,63 & 2,33 \\
\hline & & Miconia splendens * & - & - & 5,06 & 1,83 \\
\hline & & Licania gardneri & - & - & 4,67 & 1,62 \\
\hline & & Miconia tomentosa & - & - & 3,34 & 1,18 \\
\hline & & Lacistema aggregatum * & - & - & 3,14 & 1,11 \\
\hline & & Unonopsis lindmanii * & - & - & 2,95 & 1,03 \\
\hline & & Micropholis sp. & - & - & 2,29 & 0,80 \\
\hline & & Protium heptaphyllum & - & - & 2,16 & 0,76 \\
\hline & & Quiina sp. 1 * & - & - & 1,97 & 0,71 \\
\hline & & Eriotheca sp. & - & - & 1,13 & 0,39 \\
\hline & & Endlicheria sp. & - & - & 1,04 & 0,36 \\
\hline & & Guarea macrophylla & - & - & 1,01 & 0,35 \\
\hline & & Perebea cf longepedunculata * & - & - & 0,56 & 0,20 \\
\hline & & Abarema jupunba & - & - & 0,51 & 0,18 \\
\hline & & Coussarea hydrangeifolia * & - & - & 0,50 & 0,17 \\
\hline & & Myrtaceae * & - & - & 0,50 & 0,17 \\
\hline & & Ocotea sp. 3 * & - & - & 0,49 & 0,17 \\
\hline
\end{tabular}

* Espécies registradas apenas nessa classe diamétrica

\section{DISCUSSÃO}

As florestas presentes no interflúvio e na margem do rio Pacuneiro apresentaram alta similaridade florística, caracterizando-as como pertencentes à mesma unidade fitogeográfica. Este fato é reforçado pelo destaque na comunidade de espécies comuns aos dois ambientes, como é o caso de Xylopia cf. ulei Diels, Myrciaria dubia (Kunth) McVaugh e Protium pilosissimum Engl. Mesmo assim, essa formação pode apresentar subtipos florísticos e estruturais de acordo com a posição no relevo, a proximidade dos cursos d'água e o estrato analisado, apresentando predominância de algumas espécies, ou até mesmo possíveis endemismos, em determinados trechos ou estratos.

Como o clima é o mesmo e, pelo histórico da área, todos os trechos analisados são aparentemente comunidades primárias e pouco afetadas por ações antropogênicas, a composição e a estrutura de cada um dos trechos são determinadas por características de solo, ou por uma combinação de solo e regime de inundação (Richards, 1996). A floresta localizada no interflúvio não está sujeita à inundação periódica e localiza-se sobre latossolos bem drenados (textura média). Já a floresta ribeirinha sofre inundações periódicas, quando o nível d'água pode chegar a mais de $1,5 \mathrm{~m}$ do solo, e encontra-se sobre neossolos argilosos, com presença de mosqueados em profundidade, o que indica uma condição anaeróbica (Ivanauskas, 2002). Em condições desfavoráveis, a restrição ambiental exclui as espécies mais exigentes e dá uma vantagem seletiva para aquelas que são relativamente tolerantes (Richards, 1996; Huston, 1979). Pode-se considerar a inundação como um fator restritivo para a diversidade, como mostrado nos resultados.

Campbell et al. (1986) e Pires \& Koury (1958) já haviam constatado que as florestas amazônicas localizadas em áreas periodicamente inundadas têm menos espécies arbóreas e composição florística particular quando comparada àquelas sobre solos bem drenados. Em locais sujeitos à inundação, predominam poucas espécies: em Gaúcha do Norte destacaram-se em valor de importância na estrutura da comunidade Pseudolmedia laevigata Trécul no estrato superior e Zygia cataractae (Kunth) L. Rico e Sorocea klotzchiana Baill. no estrato inferior, todas exclusivas da condição ribeirinha.

No entanto, apesar da menor riqueza e diversidade, é na condição ribeirinha da bacia do Pacuneiro que encontram-se os maiores valores de área basal, devido à presença de espécies que conseguem atingir nessa condição diâmetros elevados, como é o caso de Hymenaea courbaril L., Pera schomburgkiana Müll.Arg., Aspidosperma araracanga Marc.-Ferr. e Tabebuia serratifolia G.Nicholson que apresentaram maior desenvolvimento em áreas inundáveis (hábitat preferencial). Mesmo assim, a maior biomassa da floresta nas áreas inundáveis não está correlacionada a melhores condições edáficas no conceito agrícola: o solo mais argiloso, embora apresente teores mais elevados de potássio do que o interflúvio, possui maior saturação por alumínio (Ivanauskas, 2002). 
Nas comunidades de terra firme há maior número de espécies por área, embora com menor área basal, e mais espécies com baixa densidade do que em áreas alagáveis (Richards, 1996). Na bacia do Pacuneiro, a floresta presente no interflúvio apresenta flora mais rica e típica desse ambiente, mas que mantém ligações florísticas com a condição ribeirinha. As análises mostraram que a similaridade é maior nos estratos inferiores da floresta, onde a estrutura não apresentou forte correlação com o gradiente de umidade, indicando que as espécies deste estrato estão mais sujeitas a outros fatores controladores dos padrões de distribuição, como interações competitivas por luz, predação ou herbivoria (Huston, 1979), que não foram analisadas neste trabalho.

A floresta amazônica também é definida como uma coleção de espécies de exigências ecológicas aparentemente similares, que ocorrem em combinação, flutuando na composição de um local para outro (Muniz et al., 1994). Este aspecto importante da diversidade destas florestas tem sido bastante discutido, a fim de entender como muitas espécies arbóreas, superficialmente similares, podem coexistir numa comunidade.

Em Gaúcha do Norte, as espécies congenéricas representaram mais da metade do total de espécies amostradas, o que pode indicar um possível centro de diversificação para alguns gêneros (Almeida et al., 1993). A distribuição simpátrica de espécies muito afins filogeneticamente, aparentemente contradiz a hipótese de Gause (Richards, 1996), de que nas comunidades em equilíbrio mais de uma espécie não pode ocupar o mesmo nicho. Estudos mais recentes revelaram que estas espécies, morfologicamente muito similares, ocupam ambientes físicos e bióticos levemente diferentes: espécies simpátricas podem diferir na biologia floral, fenologia, micro-hábitat, condições para a germinação das sementes, altura na maturidade ou respostas à seca ou à inundação (Rogstad, 1990; Gentry, 1992).

Nas florestas de interflúvio, poucas espécies predominaram em valor de importância, tanto pelo número de indivíduos quanto pela área basal. Esta relação foi observada por Pires \& Koury (1958), segundo os quais a fisionomia de um trecho de mata depende muito das espécies dominantes, e as 5 ou 7 espécies mais comuns geralmente representam mais da metade do número de indivíduos de uma comunidade florestal amazônica. A maioria das espécies raras representa uma minoria de indivíduos arbóreos na paisagem que elas ocupam, como apresentado na análise da curva de Lorenz (Figura 4). Para Pitman et al. (2001), embora as espécies raras contribuam significativamente para a riqueza das florestas amazônicas, maior ênfase deve ser dada a essa pequena proporção de espécies que ocorrem com alta freqüência e densidade local, formando oligarquias previsíveis que dominam milhares de quilômetros quadrados. Sendo assim, as formações que se aproximam com relação às espécies dominantes, logicamente mostrar-se-ão, no aspecto geral, relações de semelhança.
No entanto, a variação na importância de espécies já foi relatada como algo comum em vários tipos florestais, inclusive em florestas de terra firme na Amazônia (Almeida et al., 1993). Uma espécie predominante em determinado trecho pode estar quase ausente em outro vizinho, mesmo dentro do mesmo tipo de vegetação (Pires et al., 1953; Campbell et al., 1986), constituindo manchas de densidade e dominância diferentes. Segundo Almeida et al. (1993), esta variação na densidade das espécies pode estar relacionada a aspectos fitogeográficos, taxonômicos e evolutivos, ou ao mosaico sucessional (Torquebiau, 1986). Também não podem ser desconsiderados problemas relacionados ao tamanho da amostragem (Condit, 1995). Alguns modelos estocásticos de dinâmica florestal sugerem que essa imprevisibilidade na composição e estrutura da comunidade é um aspecto da diversidade deste ecossistema (Hubbel \& Foster, 1986).

As florestas de interflúvio apresentam espécies de ampla distribuição por toda a bacia do Pacuneiro, como é o caso de Amaioua guianensis Aubl. que destacou-se com alto valor de importância em qualquer estrato. Mas há aquelas que, embora ocorram por todo o interflúvio, assumem importância em trechos específicos: apenas no interflúvio da margem direita, Nectandra aff. cissiflora Nees, Miconia cf. pyrifolia Naudin e Guatteria cf. foliosa Benth. predominaram no estrato superior, e Aparisthmium cordatum Baill. e Cheiloclinium cognatum (Miers) A.C.Sm. no estrato inferior. O interflúvio da margem esquerda, por sua vez, caracterizou-se pela presença de espécies de distribuição agregada, como é o caso de Ocotea cf. glomerata (Nees) Mez e Thyrsodium spruceanum Benth. Esta última, juntamente com as espécies do gênero Trattinnickia, são localmente conhecidas como "timbori" e intensamente exploradas pelas laminadoras regionais.

A flutuação de espécies de um local para o outro também pode estar relacionada com o conceito de exclusão competitiva e na hipótese de que as comunidades se mantém num equilíbrio competitivo (Huston, 1979). Flutuações no ambiente físico e biótico estão constantemente alterando o tamanho das populações e a natureza das interações competitivas, tornando raras as situações de equilíbrio competitivo. Neste caso, há um aumento e a eventual predominância de um competidor, concomitantemente com o decréscimo de outro, e, em casos de exclusão total, a redução da diversidade.

De maneira geral, as florestas da bacia do Pacuneiro apresentaram menor número de espécies por hectare (51$66 \mathrm{spp} / \mathrm{ha}$ ) quando comparada a outras bacias hidrográficas amazônicas, refletindo assim uma baixa diversidade alfa, que é aquela medida em cada hectare amostrado no interflúvio ou na área inundável (Whittaker, 1972). Também apresentou baixa diversidade beta, considerando que esta reflete o grau de mudança na composição de espécies ao longo de um gradiente, pois o índice de diversidade para a área total manteve-se em 3,86. 


\section{ACTA AMAZONICA}

Na Amazônia, a riqueza de espécies arbóreas atinge valores desde 87 espécies por hectare no leste (Pires, 1957) a até 300 espécies por hectare no oeste (Gentry, 1988; Valencia et al, 1994; Oliveira, 1997), para árvores com DAP $>10 \mathrm{~cm}$. Também foi registrado maior número de espécies no centro e noroeste da Amazônia, do que nas partes orientais e ocidentais da região (Ducke \& Black, 1954; Salomão et al., 1988). No entanto, florestas tropicais com poucas espécies não são comuns, a não ser em áreas com fortes restrições ambientais (Richards, 1996).

A menor riqueza das florestas da microbacia do Pacuneiro pode estar relacionada com a abundância e a distribuição da precipitação (Mori et al., 1989). Estas florestas encontram-se numa zona de transição entre o clima ombrófilo e o estacional, com precipitações anuais de $1500 \mathrm{~mm}$ e 3-7 meses de período seco (Ivanauskas, 2002), o que pode ser um fator limitante para a ocorrência de muitas espécies da Floresta Ombrófila (Prance, 1990). Em todos os continentes, a diversidade de espécies da floresta tropical diminui com a estacionalidade e aumenta com a precipitação (Richards, 1996), exceto para precipitações bastante altas, em torno de $4000 \mathrm{~mm}$ por ano (Gentry, 1982; 1986).

No entanto, Oliveira \& Mori (1999) discordaram da idéia de que uma alta riqueza de espécies somente possa ocorrer em áreas com solos férteis e precipitações relativamente altas, e sugerem que a alta riqueza específica é resultante de uma combinação de heterogeneidade de hábitats e história geológica.

Ainda nesse sentido, segundo Huston (1979) a diversidade de espécies está baseada nas interações de não equilíbrio de populações competidoras, onde condições que aumentem as taxas de crescimento de espécies competidoras resultam num decréscimo da diversidade, e qualquer condição que reduza essas taxas deve manter ou permitir um aumento na diversidade. Neste caso, as florestas presentes no Alto Xingu ocupam um ambiente físico bastante homogêneo (Ivanauskas, 2002): a temperatura é alta e constante, com um suave gradiente de maior pluviosidade e menor estacionalidade na direção noroeste; não existem grandes variações altitudinais, e sim relevos planos a suave ondulados. A maior variação no ambiente físico é edáfica, onde nos interflúvios ocorrem latossolos de textura média e distróficos, e nas margens dos rios neossolos de textura mais argilosa e álicos. Assim, o ambiente físico aparentemente mais homogêneo pode estar favorecendo as taxas de crescimento de espécies competidoras, que destacam-se na estrutura de determinados trechos, e, em parte, explicar a baixa diversidade encontrada.

Para Pitman et al (2001), um grande número de estudos tem demonstrado que muitas espécies tropicais não estão distribuídas aleatoriamente em relação às variáveis ambientais, e o consenso é que esses padrões refletem hábitats preferenciais ou variações na história de vida dessas espécies. É possível que a maioria das espécies arbóreas de baixa densidade na Amazônia sejam altamente sensíveis à heterogeneidade ambiental, enquanto uma minoria de espécies comuns seja indiferente a isso. Assim, onde a heterogeneidade ambiental é baixa, ou percebida como tal pelas espécies, uma extensa área passa a ser dominada por poucas espécies comuns; onde a heterogeneidade ambiental é alta, as áreas dominadas por essas oligarquias passam a ser muito menores.

Como fator geológico, a contração das florestas tropicais, causada pelos períodos secos da era glacial durante o pleistoceno, é considerada um dos fatores de especiação (Oliveira \& Mori, 1999). Essa contração, em função da expansão do cerrado, formou ilhas de florestas (refúgios) que se tornaram zonas de especiação até nova expansão florestal (Prance, 1982; Silva et al., 1992). Conseqüentemente, as florestas situadas na borda amazônica seriam resultantes da expansão desses refúgios, e a flora local composta de espécies que sofreram um processo de seleção natural para a ocupação dessas áreas marginais, num ambiente muito diferente e distante daquele do refúgio, portanto de menor riqueza. No entanto, Gentry (1992) considera que a importância atribuída aos refúgios do Pleistoceno para a especiação tenha sido exagerada, pois a maioria das evidências botânicas para a existência e locação dos refúgios pode ser explicada, nos dias atuais, por condições de clima e solo ou por coletas concentradas em determinados locais.

A menor riqueza, bem como a dominância de poucas espécies, também prevalecem nos estágios sucessionais iniciais das florestas amazônicas (Mori et al., 1989). Saldarriaga (1987) demonstrou que poucas espécies e pequena biomassa caracterizam florestas secundárias com mais de 80 anos após o cultivo na Amazônia venezuelana. No caso das florestas da bacia do Pacuneiro, pequenos trechos do interflúvio possuem manchas de "terra preta de índio" e pedaços de cerâmica enterrados a pequena profundidade. Situada ao sul do Parque Indígena do Xingu, é possível que toda a região tenha sido explorada por diversas tribos indígenas, mas é pouco provável que o manejo realizado por essas tribos seja, isoladamente, responsável pela baixa diversidade regional.

\section{AGRADECIMENTOS}

À Fundação de Amparo à Pesquisa do Estado de Mato Grosso (FAPEMAT), pelo Auxílio à Pesquisa. À Universidade do Estado de Mato Grosso (UNEMAT), pela bolsa de iniciação científica concedida aos alunos Rodney Haulien Oliveira Viana e Geane Pereira de Freitas.

\section{BIBLIOGRAFIA CITADA}

Ackerly, D.D., Thomas, W.W., Ferreira, C.A.C.; Pirani, J.R. 1989. The Forest-Cerrado transition zone in southern Amazonia: Results of the 1985 Projeto Flora Amazônica Expedition to Mato Grosso. Brittonia, 4 (12): 113-128.

Almeida, S.S, Lisboa, P.L.B.; Silva, A.S. 1993. Diversidade florística de uma comunidade arbórea na estação científica "Ferreira Pena”, em Caxiuanã (Pará). Bolm. Mus. paraense Emilio Goeldi Ser. Botanica, 9(1): 93-128. 


\section{ACTA \\ AMAZONICA}

ESTRUTURA DE UM TRECHO DE FLORESTA

AMAZÔNICA NA BACIA DO ALTO RIO XINGU
Campbell, D.G. 1989. Brazilian Amazon. In: Campbell, D.G.; Hammond, H.D. (Eds.). Floristic Inventory of Tropical Countries New York Botanical Garden, New York, USA. p. 523-533.

Campbell, D.G., Daly, D.C., Prance, G.T.; Maciel, U.N. 1986. Quantitative ecological inventory of terra firme and várzea tropical forest on the Rio Xingú, Brazilian Amazonia. Brittonia, 38(4): 369-393.

Causton, D.R. 1988 An introduction to vegetation analysis, principles, practice and interpretation. Unwin Hyman, London, England. 342p.

CNEC 1997. Diagnóstico sócio-econômico-ecológico do Estado de Mato Grosso e assistência técnica na formulação da $2^{a}$ aproximação do zoneamento sócio-econômico-ecológico. Espacialização preliminar da vegetação do Estado do Mato Grosso. Escala 1:1.500.000

Condit, R. 1995. Research in large, long-term tropical forest plots. Trends Ecol. Evol., 10:18-22

Cronquist, A. 1988.The evolution and classification of flowering plants. The New York Botanical Garden, New York, USA. 555p.

Dubs, B. 1992. Observations on the differentiation of woodland and wet savana habitats in the Pantanal of Mato Grosso, Brasil. In: Furley, P.A.; Proctor, J.; Ratter, J.A. Nature and dynamics of forest-savanna boundaries. Chapman \& Hall, London, England. p. 417-429.

Ducke, A. \& Black, G.A. 1954. Notas sobre a fitogeografia da Amazônia Brasileira. Bolm. Tecn. Inst. Agron. Norte, 29:1-48.

Fearnside, P.M. 1990. Fire in the tropical rain forest of the Amazon basin. In: Goldammer, J.G. (Ed.). Fire in the Tropical Biota: Ecosystem Processes and Global Challenges. Springer-Verlag, Berlim. Ecol. Studies, 84:106-116

Ferreira, L.V. \& Prance, G.T. 1998. Species richness and floristic composition in four hectares in the Jaú National Park in upland forests in Central Amazonian. Biodiv. Conserv., 7 (10): 13491364 .

Gentry, A. 1982. Patterns of neotropical plant species diversity. Evol. Biol., 15:1-84.

Gentry, A. 1986. Endemism in tropical versus temperate plant communities. In . Soulé, M.E (Ed.). Conservation Biology. Sinauer Associates Inc., Sunderland, Massachusetts. p.153-537.

Gentry, A. 1988. Tree species richness of upper Amazonian forests. Proc. Natl. Acad. Sci. USA, 85:156-159.

Gentry, A. 1992. Tropical forest biodiversity: distribution patterns. Oikos, 63:19-28.

Guarim-Neto, G.; Guarim, V.L.M.S.; Prance, G.T. 1994. Structure and floristic composition of the trees of an area of cerrado near Cuiabá, Mato Grosso, Brazil. Kew Bull., 49(3): 499-509.

Haase, R. 1999. Litterfall and nutrient return in seasonally flooded and non-flooded forest of the Pantanal, Mato Grosso, Brazil. Forest Ecol. Management, 117:129-147.

Hill, M.O. 1979. TWINSPAN - A FORTRAN program for arranging multivariate data in an ordered two-way table by classification of individuals and attributes. Cornell University Ithaca, New York, USA.
Hubbel, S.P.; Foster, R.B. 1986.Commonness and rarity in a neotropical forest: implications for tropical tree conservation. In: Soulé, M.E. (Ed.). Conserv. Biol. . Sinauer Associates, Inc., Sunderland, Massachusetts. p.205-231.

Huston, M. 1979. A general hypothesis of species diversity. Amer. Naturalist, 113:81-101.

Ivanauskas, N.M. 2002. Estudo da vegetação presente na área de contato entre formações florestais em Gaúcha do Norte. Tese de Doutorado. Universidade Estadual de Campinas, Campinas. 185p.

Jaccard, P. 1912. The distribution of the flora the alpine zone. New Pbytol., 11:37-50.

Jacomine, P.K.T.; Castro Filho, C.; Moreira, M.L.C.; Vasconcelos, T.N.N.; Leite Sobrinho, J.B.P.L.; Mendes, A.M.; Silva, V. 1995. Guia para a identificação dos principais solos do Estado de Mato Grosso. PNUD/PRODEAGRO, Cuiabá, Brasil.

Köppen, W.P. 1948. Climatologia. Fondo de Cultura Economica, Mexico. $478 \mathrm{p}$.

Lamprecht, H. 1962. Ensayo sobre unos métodos para el analisis estructural de los bosques tropicales. Acta Cient. Venez., 13:57-65.

Maciel, U.N.; Lisboa, P.L.B. 1989. Estudo florístico de 1 hectare da mata de terra firme no Km 15 da Rodovia Presidente MédiciCosta Marques (RO 429), Rondônia. Bolm. Mus. paraense Emílio Goeldi Ser. Botanica, 5 (1):25-37.

Marimon, B.S.; Felfilli, J.M. 1997. Structure of a monodominant forest of Brosimum rubescens Taub. in Nova Xavantina-MT, Brazil. In: Imaña-Encinnas, J.; Kleinn,C. (Orgs.) Internacional Symposium on Assessment and Monitoring of Forests in Tropical Dry Regions with Special Reference to Gallery Forests. UnB, Brasília, Brasil. p.215-230.

Marimon, B.S.; Varella, R.F.; Marimon Júnior, B. 1998. Fitossociologia de uma área de cerrado de encosta em Nova Xavantina, Mato Grosso. Bolm. Herb. Ezechias Paulo Heringer, 3: 82-101.

Marimon, B.S.; Felfilli, J.M. 2000. Distribuição de diâmetros e alturas na floresta monodominante de Brosimum rubescens Taub. na Reserva Indígena Areões, Água Boa-MT, Brasil. Revta Arvore, 24(2): 143-150.

Martini, A.; Rosa, N.; Uhl, C. 1998. Espécies de árvores potencialmente ameaçadas pela atividade madeireira na Amazônia. Série Amazônia, 11. IMAZON, Belém, Brasil.

McCune, B.; Mefford, M.J. 1997. PC-ORD. Multivariate Analysis of Ecological Data, v.3.12. MjM Software Design, Oregon.

Mori, S.A.; Boom, B.M.; Carvalino, A.M.; Santos, T.S. 1983. Ecological importance of Myrtaceae in eastern Brazilian wet forests (notes). Biotropica, 15(1):68-69.

Mori, S.A.; Rabelo, B.V.; Tsou, C.H.; Daly, D. 1989. Composition and structure of an eastern Amazonian forest at Camaipi, Amapá, Brasil. Bolm. Mus. paraense Emilio Goeldi, 5(1): 3-18.

Mueller-Dombois, D.; Ellemberg, H. 1974. Aims and methods vegetation ecology. Wiley, New York, USA. 347p.

Muniz, F.H.; Cesar, O.; Monteiro, R. 1994. Fitossociologia da vegetação arbórea da Reserva Florestal do Sacavém, São Luís, Maranhão (Brasil). Acta Amazonica, 24 (3/4):219-236. 


\section{ACTA AMAZONICA}

Nascimento, M.T.; Cunha, C.N. 1989. Estrutura e composição florística de um cambarazal no Pantanal de Poconé, MT. Acta bot. Brasilica, 3(1):3-23.

Nascimento, M.T.; Saddi, N. 1992. Structure and floristic composition in area of cerrado in Cuiabá- MT, Brazil. Revta bras. Bot., 15(1):47-55.

Oliveira, A. A. 1997. Diversidade, estrutura e dinâmica do componente arbóreo de uma floresta de terra firme de Manaus, Amazonas. Tese de Doutorado. Instituto de Biociências da Universidade de São Paulo. 187p.

Oliveira, A. A.; Mori, S. A. 1999. A central Amazonian terra firme forest. I. High tree species richness on poor soils. Biodiversity and Conservation, 8:1219-1244.

Oliveira-Filho, A.T. 1989. Composição florística e estrutura comunitária da floresta de galeria do córrego da Paciência, Cuiabá-MT. Acta bot. Brasilica, 3(1):91-112.

Oliveira-Filho, A.T. 1992. The vegetation of Brazilian "murunduns" the island-effect on the plant community.J. Trop. Ecol., 8:465-486.

Oliveira-Filho, A.T. \& Martins, F.R. 1986. Distribuição, caracterização e composição florística das formações vegetais da região da Salgadeira, na Chapada dos Guimarães (MT). Revta brasil. Bot., 9:207-223.

Palmer, M. 2001. Ordination Methods for Ecologists. Disponível na Internet via WWW. URL: www.oakstate.edu/artsci/botany/ ordinate.

Pielou, E.C.1984. The interpretation of ecological data. John Wiley \& Sons, New York, USA. 263p.

Pinho, D.V.; Vasconcellos, M.A.S. 1997. Manual de Economia. Saraiva, São Paulo, Brasil. 653p.

Pinto, J.R.R.; Oliveira-Filho, A.T. 1999. Perfil florístico e estrutura da comunidade arbórea de uma floresta de vale no Parque Nacional da Chapada dos Guimarães, Mato Grosso, Brasil. Revta bras. Bot., 22(1):53-67.

Pires, J.M. 1957. Noções sobre ecologia e fitogeografia da Amazônia. Norte Agronômico, 3:37-53.

Pires, J.M.; Dobzhansky, T.; Black, G.A. 1953. An estimate of the number of species of trees in an Amazonian forest community. Bot. Gaz., 114(4):467-477.

Pires, J.M.; Koury, H.M. 1958. Estudo de um trecho de mata de várzea próximo a Belém. Bolm. tecn. Inst. Agron. Norte, 36:3-44.

Pitman, N.C.A.; Terborgh, J.W.; Silman, M.R., Núñez, P.V.; Neill, D.A.; Cerón, C.E.; Palacios, W.A.; Aulestia, M. 2001. Dominance and distribution of tree species in upper amazonian terra firme forests. Ecology, 82(8):2101-2117.

Prance, G.T. 1982. Forest refuges: evidence from woody angiosperms. In: Prance, G.T. (Ed.). Biological diversification in the tropics. Columbia University Press, New York, USA. p.137-157.

Prance, G.T. 1990. The floristic composition of the forests of central Amazonian Brazil. In: Gentry, A.H. (Ed.). Four Neotropical Rainforests. Yale University Press, New Haven, USA. 627p.

Prance, G.T.; Schaller, G.B. 1982. Preliminary study of some vegetation types of the Pantanal, Mato Grosso, Brazil. Brittonia, 4:228-251.

Richards, P.W. 1996. The Tropical Rain Forest. 2ed. Cambridge University Press, Cambridge, USA. 575p.
Rodrigues, R.R.; Leitão Filho, H.F. (Eds.) 2000. Matas Ciliares: Conservação e Recuperação. EDUSP/FAPESP, São Paulo, Brasil. 320p.

Rogstad, S.H. 1990. The biosystematics and evolution of the Polyalthia hypoleuca species complex (Annonaceae) of Malesia. II. Comparative distribution ecology.J. Trop. Ecol., 6:387-408.

Saldarriaga, J.G. 1987. Recovery following shifting cultivation. In: Jordan, C.F. (Ed.) Amazonian rain forests. Springer-Verlag, New York, USA. p.24-33.

Salis, S.M.; Pott, V.J.; Pott, A. 1999. Fitossociologia de formações arbóreas da bacia do alto Paraguai, Brasil. In: II Simpósio sobre recursos naturais e sócio-econômicos do Pantanal. EMBRAPAPantanal, Corumbá, Brasil. p.357-374.

Salomão, R.P.; Lisboa, P.L.B. 1988. Análise ecológica da vegetação de uma floresta pluvial tropical de terra firme, Rondônia. Bolm. Mus. paraense Emílio Goeldi Ser. Botanica, 4 (2):195-233.

Salomão, R.P.; Silva, M.F.F.; Rosa, P.L.B. 1988. Inventário ecológico em Floresta Pluvial Tropical de Terra Firme, Serra Norte, Carajás, Pará Bolm. Mus. paraense Emílio Goeldi Ser. Botanica, 4 (1):1-46.

SEPLAN/MT. 1999. Dados secundários do DSEE/MT: Zoneamento -Divulga. CD-Rom. Versão 1.01.

Shepherd,G.J. 1994. FITOPAC: Manual do Usuário. Departamento de Botânica, Universidade Estadual de Campinas, Campinas, Brasil.

Silva, A.S.L, Lisboa, P.L.B.; Maciel, U.N. 1992. Diversidade florística e estrutura em floresta densa da bacia do Rio Juruá. Bolm. Mus. paraense Emílio Goeldi, 8(2): 203-258.

SÆrensen, T. 1948. A method of establishing groups of equal amplitude in plant sociology based on similarity of species content. Det. Kong. Danske Vidensk. Selsk. Biol. Skr. (Copenhagen), 5(4):1-34.

Swaine, M.D.; Lieberman, D.; Putz, F.E. 1987. The dynamics of tree populations in tropical forest. J. Trop. Ecol., 3:359-366.

Torquebiau, E.F. 1986. Mosaic patterns in dipterocarp rain forest in Indonesia, and their implications for practical forestry. $J$. Trop. Ecol., 2:301-325.

Valencia, R.; Balslev, H.; Paz Y Mino, G. C. 1994. High tree alphadiversity in Amazonian Ecuador. Biodiv. Conserv. 3: 21-28.

Valentin, J.L. 2000. Ecologia numérica: uma introdução à análise multivariada de dados ecológicos. Interciência, Rio de Janeiro, Brasil. 117p.

van den Berg, E. 1995. Estudo florístico e fitossociológico de uma floresta ripária em Itutinga, MG, e análise das correlações entre variáveis ambientais e a distribuição das espécies de porte arbóreo-arbustivo. Dissertação de mestrado, Universidade Federal de Lavras, Lavras.

van Tongeren, O. F.R. 1995. Cluster analysis. In: (Jongman, R.H.G; Ter Braak, C.J.F.; van Tongeren, O.F.R. (Eds.). Data analysis in community and landscape ecology. Cambridge University Press, Cambridge, USA. p.174-212.

Whittaker, R.H. 1972. Evolution and measurement of species diversity. Taxon, 21:213-251.

\section{RECEBIDO EM 24/07/2002 ACEITO EM 02/04/2004}


